\title{
Crack initiation under thermal fatigue: An overview of CEA experience. Part I: Thermal fatigue appears to be more damaging than uniaxial isothermal fatigue
}

\author{
A. Fissolo ${ }^{\mathrm{a}, *}$, S. Amiable ${ }^{\mathrm{b}}$, O. Ancelet ${ }^{\mathrm{a}}$, F. Mermaz ${ }^{\mathrm{c}}$, J.M. Stelmaszyk $^{\mathrm{c}}$, A. Constantinescu $^{\mathrm{b}}$, C. Robertson ${ }^{\mathrm{d}}$, \\ L. Vincent ${ }^{\mathrm{d}}$, V. Maillot ${ }^{\mathrm{d}}$, F. Bouchet ${ }^{\mathrm{d}, 1}$ \\ ${ }^{a}$ Commissariat à l'Energie Atomique - Saclay, Département de Modélisation de Systèmes et Structures, Service d'Etudes Mécaniques et Thermiques, Laboratoire d'Intégrité \\ des Structures et de Normalisation, Bat 607, 91191 Gif sur Yvette Cédex, France \\ ${ }^{\mathrm{b}}$ Ecole Polytechnique, Laboratoire de Mécanique des Solides - CNRS UMR 7649, École Polytechnique, 91128 Palaiseau Cédex, France \\ ' Institut de Radioprotection et de Sûreté Nucléaire, BP17 - 92262 Fontenay-aux-Roses Cédex, France \\ ${ }^{\mathrm{d}}$ Commissariat à l'Energie Atomique - Saclay, Service de Recherches métallurgiques Appliquées, Laboratoire du Comportement et du Dommage, Bat 455, \\ 91191 Gif sur Yvette Cédex, France
}

For nuclear reactor components, uniaxial isothermal fatigue curves are used to estimate the crack initiation under thermal fatigue. However, such approach would be not sufficient in some cases where cracking was observed. To investigate differences between uniaxial and thermal fatigue damage, tests have been carried out using the thermal fatigue devices SPLASH and FAT3D: a bi-dimensional (2D) loading condition is obtained in SPLASH and crack initiation is defined as the first $150-\mu \mathrm{m}$ surface cracks, whereas a tri-dimensional (3D) loading condition is obtained in FAT3D and crack initiation refers to the first 2-mm surface crack.

All the analysed tests clearly show that for identical levels of strain, the number of cycles required to achieve crack initiation is significantly lower in thermal fatigue than in uniaxial isothermal fatigue.

The enhanced damaging effect probably results from a pure mechanical origin: a nearly perfect biaxial state corresponds to an increased hydrostatic stress. In that frame, a Part II accompanying paper will be dedicated to investigate accurately on multiaxial effect, and to improve thus estimation of crack initiation under thermal fatigue.

\section{Introduction}

Thermal fatigue induces in-service damage in various industrial components, such as moulds, rolling mill cylinders or turbine blades [1-3]. It also occurs in different types of nuclear reactor components. In the case of pressurized water reactors (PWRs), networks of cracks may appear in auxiliary cooling lines, close to coldwater injection sites, in spite of the relatively small temperature fluctuations [4-7]. A multi-discipline strategy has been adopted by CEA to investigate thermal fatigue [8].

In France, estimations of fatigue resistance of nuclear reactor components are based both on the RCC-M design code (close to the ASME code) and on the French RCC-MR code. The first was specifically developed for PWRs design. The second was developed for the fast breeder reactor design. Such methodologies assume that thermal fatigue resistance on components can be directly extrapo-

\footnotetext{
* Corresponding author. Tel.: +3316908 31 02; fax: +3316908 8784 .

E-mail address: antoine.fissolo@cea.fr (A. Fissolo).

${ }^{1} \mathrm{~F}$. Bouchet was in charge of SPLASH facility tests, unfortunately died through a long and painful illness.
}

lated from classical push-pull tests (performed with stress or strain range controls). However, cracking damage in some cases (RHRS, etc. ${ }^{2}$ ), resulting from thermal fatigue loading, would indicate the necessity to investigate such hypotheses more precisely.

The present study focuses on crack initiation under thermal fatigue using SPLASH and FAT3D facilities [9-11]. Experimental tests are carried out for initiating crack damage and for developing networks of cracks under thermal fatigue loading. In the first test, 2D rectangular section specimens were used [12]. On the second test, although the specimen is a simple tube, 3D loadings were applied because local gradients are combined with global gradients [13-15]. In addition, an important push-pull test campaign was also conducted to investigate a potential discrepancy between thermal and isothermal fatigue. More tests were performed for both conditions and specimens taken from the same fabrication, so as to prevent chemical composition or fabrication variability from affecting the interpretation of the results.

A definition for crack initiation needs to be defined first.

\footnotetext{
${ }^{2}$ Reactor heat removal system.
} 


\section{Preliminary observations on crack initiation}

First, it is important to recall that crack initiation has not established physical basis. Yet, it is usually referred to phenomenological criteria and experimental observation techniques available. For example, industry often refers to several millimetre long cracks, detected using a non-destructive technique, such as ultra-sound detection (Fig. 1a). Others techniques are dye-penetrant testing, eddy-currents, etc. For the engineer, a crack initiation is related to the apparition of a "significant crack" for the integrity of the structure, i.e. altering its mechanical response to external loadings. In that instance, approaches based on fracture mechanics are applied to ensure integrity of the component.

Such definition is not sufficient for the metallurgist, since a significant evolution can be detected a very long time before "conventional" initiation. In our tested conditions, very intense slip markings are clearly evidenced in the surface after only 1,000 thermal cycles [10], whereas the first $50-\mu \mathrm{m}$ long crack is detected after 70,000 cycles (Fig. 1b). Let us note that the same evolution is observed in isothermal fatigue [16]. In early stages, micro-cracking can be assimilated to localized surface displacements with dimensions smaller than the distance to major barriers (as grain or twin boundaries). When stress level is sufficiently large, initiated cracks can cross over the major barriers. When stress level is very low, initiated cracks can be blocked on micro-structural barriers for the rest of the component's lifetime [17]. In that instance, all the cracks can be stopped but no propagation and hence no initiation occurs (even after a very high number of cycles) from an engineering point of view. In the high cycle fatigue regime, it was well established that the crack initiation stage, i.e. prior to propagation, could correspond to more than $90 \%$ of the total component life [16].

\section{Experiences}

First, it is important to notice that a different approach of crack initiation and damage is used on the two tests, as illustrated in Fig. 1:

(1) On SPLASH specimens, the number of cycles to initiation $N_{i}$ is determined from observations with optical microscopy. It is considered that initiation occurs when at least one of $50-150-\mu \mathrm{m}$ crack length is observed at the surface ( half length in the deep direction) [10]. Such definition corresponds to about one to two times the grain diameter.

(2) On FAT3D specimens, the number of cycles to initiation $N_{i}$ is determined by "visual observations". It is considered that initiation occurs when at least one of 2-mm crack length is observed at the surface [14].

\subsection{SPLASH tests}

Fig. 2 presents the SPLASH testing facility and the SPLASH specimen. The SPLASH testing facility was based on a previous test rig developed by Marsh [18].
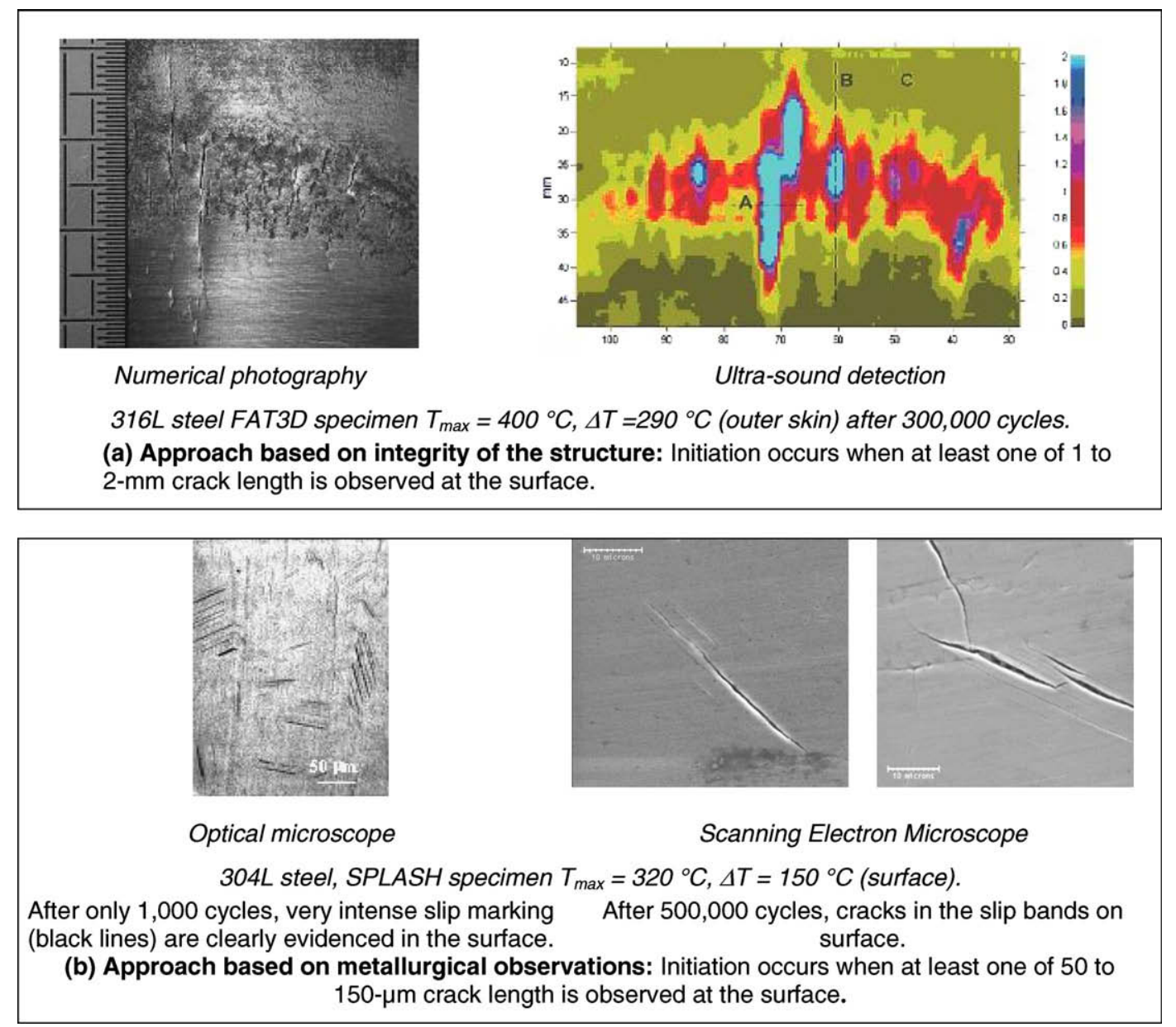

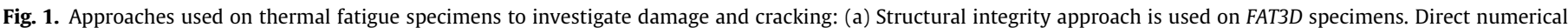

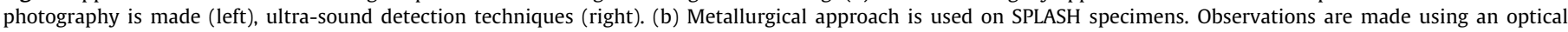
microscope or a scanning electron microscope. 
The aim of this experiment is to understand the conditions for the formation of crack networks under cyclic thermal shocks and to reproduce in laboratory conditions the damage observed on real structures $[6,19]$. Observation and analysis of these networks of cracks have already been published; including some important results reported in [10].

The specimens are massive, rigid bars $\left(240 \times 30 \times 20 \mathrm{~mm}^{3}\right)$ continuously heated by an electrical DC current and cyclically cooled by water sprayed on the two opposites faces of the specimen, as displayed in Fig. 2.

Thermal down-shocks produced by cyclic water spraying induce large temporal and spatial gradients: the cooling-rate is about $600{ }^{\circ} \mathrm{C} / \mathrm{s}$ and the gradient along the specimen depth is approximately $100{ }^{\circ} \mathrm{C} / \mathrm{mm}$. The thermal loading zone is confined to a few square millimetres on the surface and a few millimetres in depth. These loading conditions yield a small-localized plastic zone, where the crack network evolves. The temporal surface temperature range and temperature gradient during quenching are nearly equal. A temporal temperature range of $150^{\circ} \mathrm{C}$ in surface roughly corresponds to a $160{ }^{\circ} \mathrm{C}$ gradient in the thickness direction, since temperatures at the end of quenching are respectively $170^{\circ} \mathrm{C}$ ( $T_{\max }=320^{\circ} \mathrm{C}$ before quenching) in surface and $330^{\circ} \mathrm{C}$ in the specimen centre.

Two types of specimens are used: calibration specimens and endurance specimens. Both are equipped with K-type thermocouples brazed in depth, at 3 and $7 \mathrm{~mm}$ from the left and right surfaces. One thermocouple is also placed in the specimen centre. To insure accurate temperature measurements, thermocouples are placed in machined grooves, poured with a high conductivity metal. Calibration specimens also support $\mathrm{K}$ thermocouples brazed at the surface, and are used to determine the parameters of the water spray necessary to obtain the selected temporal temperature range $\Delta T$ at the surface. Those $\mathrm{K}$ thermocouples are not used on the endurance specimens, as they could induce premature crack initiation.

To obtain complete temperature maps on the surface and to verify thermocouple measurements, additional temperature measurements are also performed on the surface of the quenched zone using an infra-red camera [20].

Steels studied here are AISI 304L and AISI 316L(N) type austenitic stainless steels, with an average grain size of about $50-\mu \mathrm{m}$. The chemical composition of the steels is specified in Table 1 .
After crack initiation, crack growth, coalescence and finally networks of cracks are produced. At the end of the test, the 3D character of the networks of cracks is examined. The morphological parameters are determined, using a step-by-step removal of thin layers. For more information, one can refer to [12,21]. The present study only deals with crack initiation.

Fig. 3 gives the evolution of the temperature range as a function of the number of cycles to crack initiation. As the temperature range increases, a very sharp decrease of the number of cycles to initiation $N_{i}$ is observed. When temporal $\Delta T$ on surface ranges from 100 to $125^{\circ} \mathrm{C}$, no cracks are detected, even after $10^{6}$ cycles, whereas with a $\Delta T$ of $300^{\circ} \mathrm{C}$, initiation occurs after only $6000 \mathrm{cy}-$ cles when $T_{\max }=550^{\circ} \mathrm{C}$. As for isothermal fatigue, a fatigue limit can be clearly defined: it simply corresponds to the temperature range for which no cracking is observed.

Only the last testing campaign, performed at the maximum temperature of $320^{\circ} \mathrm{C}$ with $304 \mathrm{~L}$ steel specimens is analysed (Fig. 3b). This choice was made to ensure that all the thermal fatigue tests have been performed under strictly identical conditions (same water spray pistols, same electrical conditions, etc.). Furthermore, a comparison between thermal fatigue and isothermal push-pull tests is performed on specimens taken only from the same plate of $304 \mathrm{~L}$ steel, in order to avoid a possible variability effect.

\subsection{FAT3D tests}

Fig. 4 presents the FAT3D facility and principle. Specimens are $360-\mathrm{mm}$ long tubes, with a $170-\mathrm{mm}$ outer diameter and a 6.7$\mathrm{mm}$ wall thickness (Fig. 4). The main goal of this test is to evidence the role of 3D loadings on damage. In addition, the loading configurations are simple enough to be reproduced by numerical simulations. To obtain a homogeneous heating, specimen is placed in an oven. Cold water is periodically injected on the inner skin, at a single and fixed position. More precisely, the water-quenched boundary roughly has a parabolic shape. This effectively generates 3D loadings, since local gradients ( $T$ differences between inner and outer skins) combine with global gradients ( $T$ differences between the sides of the tube). Obviously, as for SPLASH tests, the thermal cycle in FAT3D test includes a cooling part and a heating part.

As for the SPLASH test, a calibration specimen is used to determine thermal loading. That specimen is equipped with $19 \mathrm{~K}$ a

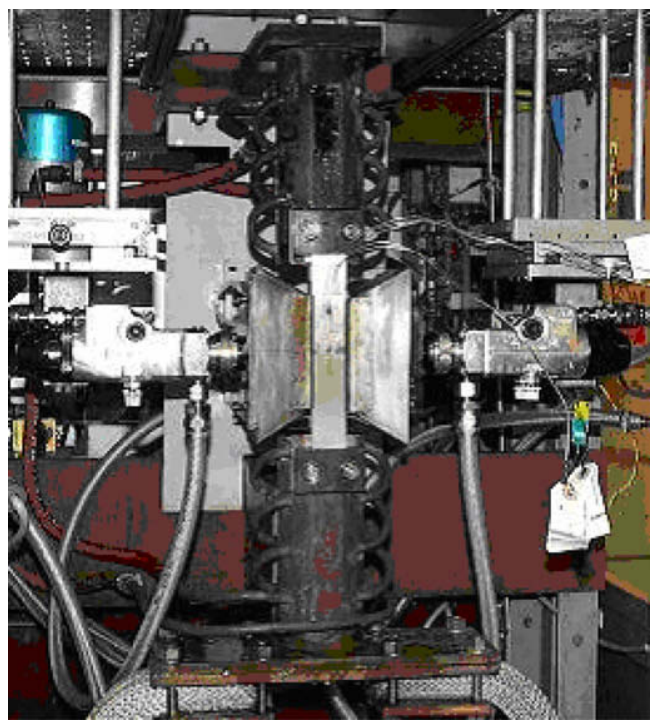

b

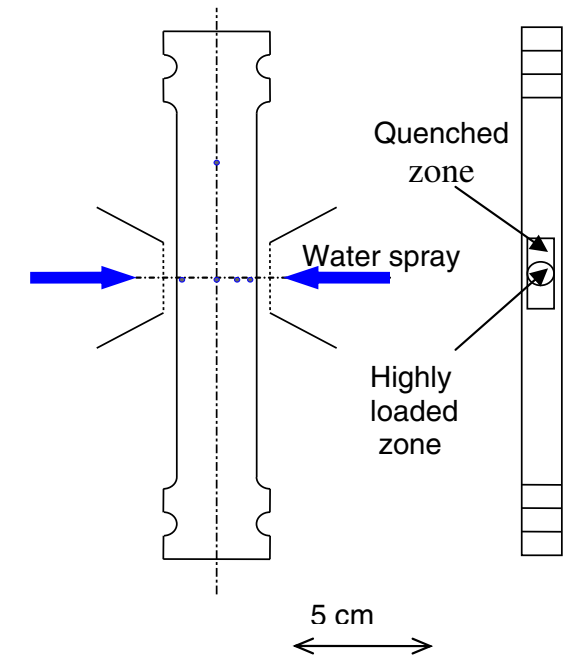

Fig. 2. SPLASH facility (left) and specimen geometry (right). 
Table 1

Chemical compositions (wt \%) of $304 \mathrm{~L}$ and $316 \mathrm{~L}(\mathrm{~N})$ stainless steels

\begin{tabular}{|c|c|c|c|c|c|c|c|c|c|c|}
\hline & $C$ & Mn & $\mathrm{Si}$ & $\mathrm{Cr}$ & $\mathrm{Ni}$ & Mo & $\mathrm{S}$ & $P$ & $\mathrm{~N}$ & $\mathrm{Fe}$ \\
\hline $304 \mathrm{~L}$ & 0.031 & 1.48 & 0.55 & 19.4 & 8.6 & 0.23 & 0.003 & 0.028 & 0.058 & Balance \\
\hline $316 \mathrm{~L}(\mathrm{~N})$ & 0.024 & 1.82 & 0.46 & 17.44 & 12.33 & 2.3 & 0.001 & 0.003 & 0.06 & Balance \\
\hline
\end{tabular}
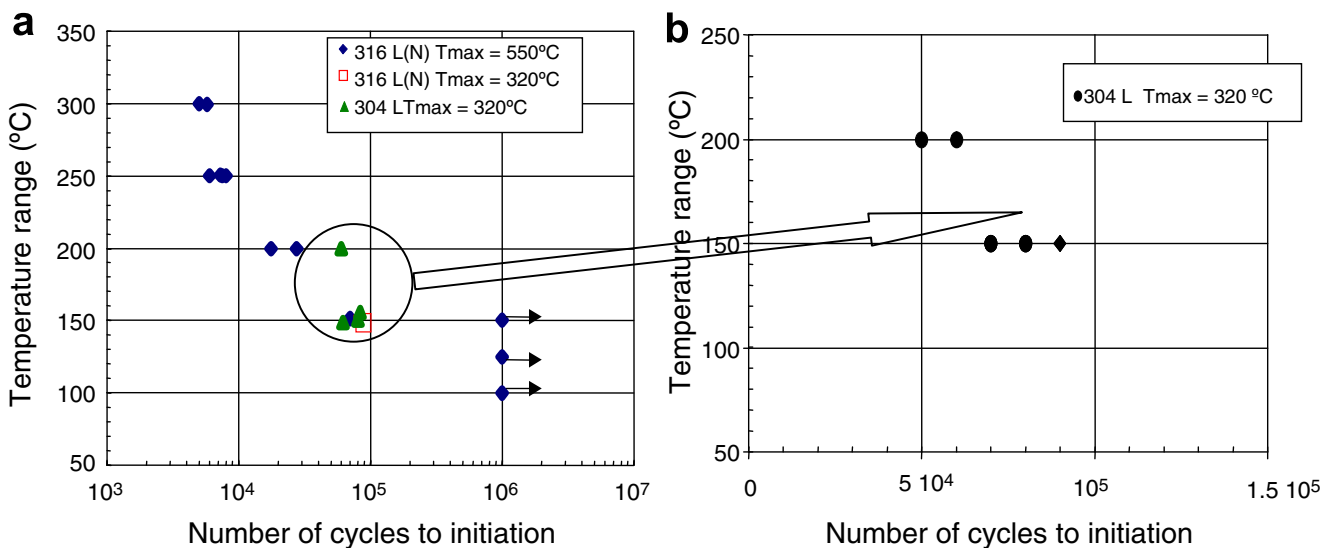

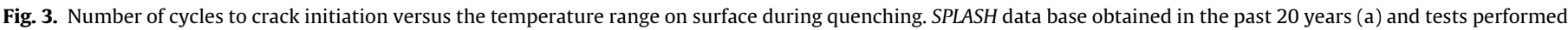
only on $304 \mathrm{~L}$ steel (b).

a

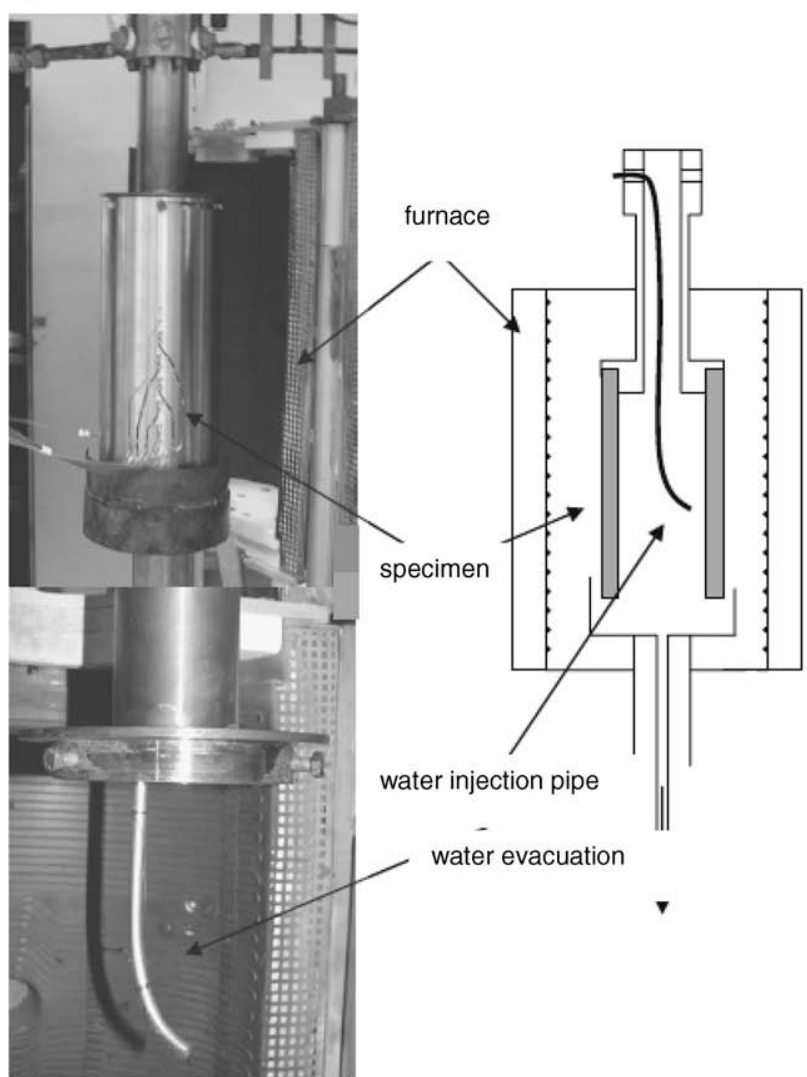

b

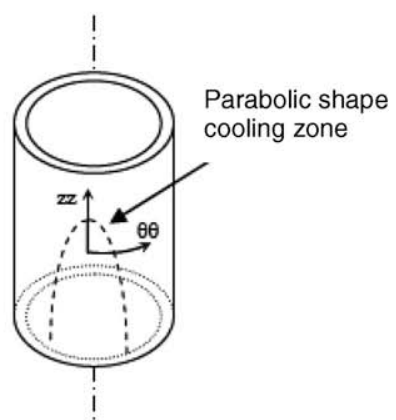

C

cold water injection

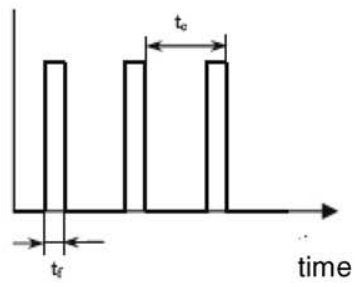

Fig. 4. $F A T 3 D$ facility and principle.

thermocouples placed in the outer skin and across the wall thickness, at the position of the cooling zone $(0.7$ and $3.5 \mathrm{~mm}$ from the internal skin). In order to place thermocouples through the thick- ness, a specific hole is machined and plugged with metal. For each fatigue experiment, the FAT3D endurance specimen are also equipped with 19 thermocouples, albeit placed on the outer skin only. 
The cooling zone is detailed on Fig. $4 \mathrm{~b}$. The top part has the highest load, in contrast with the SPLASH 2D specimen, where the highest load zone occurs in the centre of the quenched zone.

Three tests have been performed on $316 \mathrm{~L}$ steel specimens. Chemical composition is given in Table 2 .

For each test, data presented in Table 3 show:

(1) The number of cycles for which no cracks are detected.

(2) The number of cycles where one (or several) $\operatorname{crack}(\mathrm{s})$ is detected, that occurrence corresponding to the first crack observation.

(3) The highest coordinate- $Z$ where the last crack is observed at the end of the tests. These cracks are about $2 \mathrm{~mm}$ long in the surface.

These results are compared with uniaxial low cycle fatigue data (strain control conditions) obtained on specimens taken from the same 316L plate. LCF tests have been performed at room temperature, instead of the temperature representative of the thermal cycling (for example, at the average temperature of the cycle). However, RCC-MR data shows only a slight temperature effect for fatigue life: LCF at $450{ }^{\circ} \mathrm{C}[22,23]$ corresponds roughly to LCF at $20^{\circ} \mathrm{C}$ by taking $N_{\mathrm{F}} / 2$ instead of $N_{\mathrm{F}}$ (Fig. 5 ).

Indeed, to compare fatigue life on TF with fatigue life on LCF, the estimation of a "reference temperature" for LCF is not easy. However, the minimum temperature seems to be a more relevant choice: the water quenched zone is mainly loaded under tension during the cooling stage and mainly under compression during the heating stage. Table 3 shows that minimum and average temperatures in the outer wall are lower than $450{ }^{\circ} \mathrm{C}$ (outer minimum temperature $=$ outer maximum temperature $-\Delta T$ ), i.e. closer to $200{ }^{\circ} \mathrm{C}$ and $300^{\circ} \mathrm{C}$, respectively. In addition, the inner-wall temperatures are obviously even lower. As a result, the comparison with LCF at $450^{\circ} \mathrm{C}$ and $N_{\mathrm{F}}$, or with LCF at room temperature and $N_{\mathrm{F}} / 2$ would be representative and somewhat conservative to estimate number of cycles to initiate crack on TF.

Furthermore, as suggested by the RCC-MR data, the effect of temperature on hardening is negligible in the $20-450{ }^{\circ} \mathrm{C}$ temperature range. Therefore, the mechanical constitutive law is simply fitted to room temperature LCF data.

As FAT3D tests are "structure tests", trends directly extrapolated from tests do not provide useful information.

Table 2

Chemical composition of 316L steel used for FAT3D tests (in wt\%)

\begin{tabular}{llllllllll}
\hline $\mathrm{C}$ & $\mathrm{Mn}$ & $\mathrm{Si}$ & $\mathrm{Cr}$ & $\mathrm{Ni}$ & $\mathrm{Mo}$ & $\mathrm{S}$ & $\mathrm{P}$ & $\mathrm{Co}$ & $\mathrm{Fe}$ \\
\hline 0.051 & 2.14 & 0.39 & 16.13 & 8.10 & 2.23 & 0.010 & 0.015 & 0.013 & Balance \\
\hline
\end{tabular}

Table 3

FAT3D main experimental conditions and results

\begin{tabular}{|c|c|c|c|c|c|c|}
\hline & \multicolumn{2}{|c|}{ FAT3D-1 } & \multicolumn{2}{|c|}{ FAT3D-2 } & \multicolumn{2}{|c|}{ FAT3D-3 } \\
\hline Total cycle duration $t_{\mathrm{c}}+t_{\mathrm{f}}(\mathrm{s})$ & \multicolumn{2}{|c|}{190} & \multicolumn{2}{|c|}{130} & \multicolumn{2}{|c|}{91} \\
\hline Cooling duration $t_{\mathrm{f}}(\mathrm{s})$ & \multicolumn{2}{|c|}{15} & \multicolumn{2}{|c|}{15} & \multicolumn{2}{|c|}{11} \\
\hline Outer maximum temperature $\left({ }^{\circ} \mathrm{C}\right)$ & \multicolumn{2}{|c|}{530} & \multicolumn{2}{|c|}{470} & \multicolumn{2}{|c|}{440} \\
\hline Outer skin $\Delta T\left({ }^{\circ} \mathrm{C}\right)$ & \multicolumn{2}{|c|}{360} & \multicolumn{2}{|c|}{290} & \multicolumn{2}{|c|}{220} \\
\hline $\begin{array}{l}\text { (1) Number of cycles for which no } \\
\text { cracks are detected }\end{array}$ & \multicolumn{2}{|c|}{3800} & \multicolumn{2}{|c|}{21,417} & \multicolumn{2}{|c|}{14,186} \\
\hline $\begin{array}{l}\text { (2) Number of cycles with crack } \\
\text { length on surface }(\mathrm{mm})\end{array}$ & 11,845 & 30 & 30,093 & 15 & 22,923 & 6 \\
\hline Total number of cycles & \multicolumn{2}{|c|}{17,532} & \multicolumn{2}{|c|}{30,093} & \multicolumn{2}{|c|}{48,147} \\
\hline $\begin{array}{l}\text { (3) The highest height- } Z \text { where the } \\
\text { last crack is observed when test } \\
\text { is ended }(\mathrm{mm}) \text { left-side/right- } \\
\text { side }\end{array}$ & 195 & 185 & 207 & 210 & 158 & 169 \\
\hline
\end{tabular}

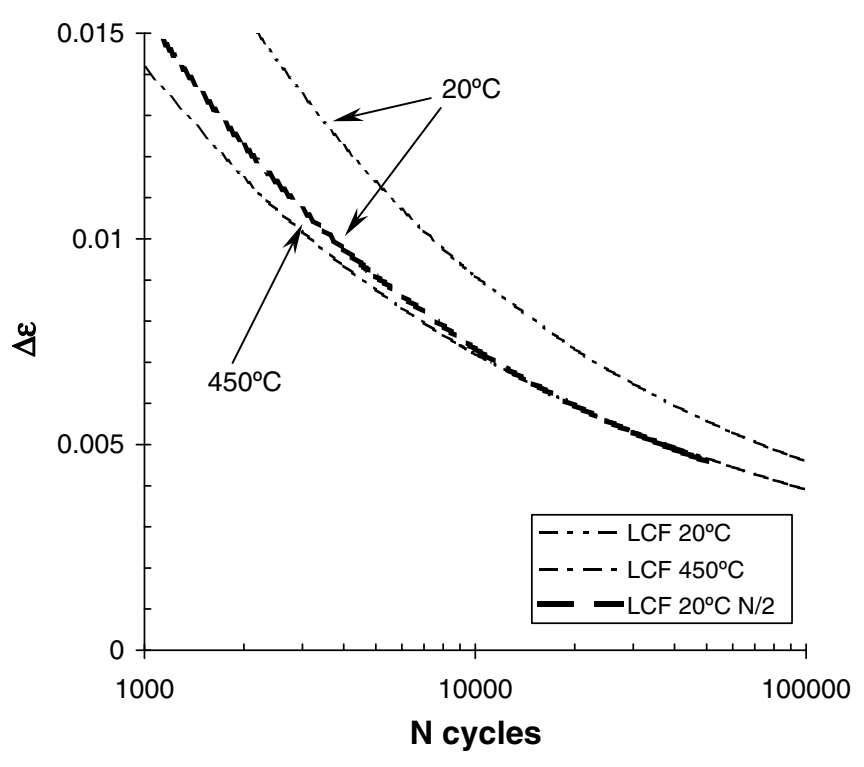

Fig. 5. Temperature effect for low cycle fatigue on $316 \mathrm{~L}$ steel - experimental RCCMR curves. Comparison between $450{ }^{\circ} \mathrm{C}-N_{\mathrm{F}}$ curve, $20^{\circ} \mathrm{C}-N_{\mathrm{F}}$ curve and $20^{\circ} \mathrm{C}-N_{\mathrm{F}} /$ 2 curve.

The next part deals with thermal and mechanical analysis of both SPLASH and FAT3D results.

\section{Thermal and mechanical analysis}

All the computations have been carried out using the object-oriented CEA finite element software CASTEM [24]. The same method was employed for both tests.

\subsection{Assumptions}

The thermo-mechanical state of specimens is determined using the three following assumptions:

(1) Thermal loading and mechanical loading are assumed to be uncoupled. This assumption is based on the negligible thermal heating due to the inelastic deformation, compared to the global heating problem. So, two uncoupled computations are performed: first a thermal analysis, then a mechanical analysis using the previously computed temperature field as input parameters.

(2) The stress-strain behaviour is assumed to be unaffected by the damage evolution. This assumption has already been validated in a series of papers $[25,26]$.

(3) A stabilized stress-strain behaviour is obtained after a short transition period, as in the RCC-MR method [22] (see the Section 5). As previously observed on $316 \mathrm{~L}(\mathrm{~N})$ steel [27], the evolution of stress in a cyclic experiment is quite complex. It can be typically described using a series of superposed hardening laws as proposed in [28]. Therefore, it is assumed that the behaviour of the material is stabilized after a first hardening period and that all computations are representative of that regime.

More precisely, two types of 3D mechanical calculations have been conducted: the first is a pure elastic calculation to be applied using the French code RCC-MR estimation, which is based on the modified Poisson coefficient [29,30], the second is an elasto-plastic calculation based on stabilized cyclic elasto-plastic behaviour (non-linear kinematic law). 
Regarding elasto-plastic behaviour, the elasto-plastic constitutive law is fitted on low cycle fatigue test results at $N_{\mathrm{F}} / 2$. It is given by: $\underline{\sigma}=\underline{C}\left(\underline{\varepsilon}-\underline{\varepsilon}^{\text {th }}-\underline{\varepsilon}^{\mathrm{p}}\right)$ where $\underline{\underline{C}}$ is the stiffness matrix $6 \times 6, \underline{\sigma}, \underline{\varepsilon}$ are, in this case, taken as stress and strain vectors.

$\underline{\underline{\varepsilon^{\dot{p}}}}=\lambda \frac{\partial f}{\partial \underline{\underline{\sigma}}}$

$f=\sqrt{3 J_{2}(\underline{\underline{\sigma}}-\underline{\underline{X}})}-\sigma_{\mathrm{y}}$

$\underline{\underline{\dot{X}_{i}}}=c_{i}\left(\frac{2}{3} a_{i} \underline{\underline{\dot{\varepsilon}}}-\underline{\underline{X}} \dot{\underline{p}}\right)$

$\underline{\underline{X}}=\sum_{i} \underline{\underline{X_{i}}}$

$\underline{\underline{C}}=\left(\begin{array}{cccccc}\lambda+2 G & \lambda & \lambda & 0 & 0 & 0 \\ \lambda & \lambda+2 G & \lambda & 0 & 0 & 0 \\ \lambda & \lambda & \lambda+2 G & 0 & 0 & 0 \\ 0 & 0 & 0 & 2 G & 0 & 0 \\ 0 & 0 & 0 & 0 & 2 G & 0 \\ 0 & 0 & 0 & 0 & 0 & 2 G\end{array}\right)$

with: $p=\int_{0}^{t} \sqrt{\frac{2}{3} \underline{\underline{\dot{\varepsilon} p}}}: \stackrel{\underline{\dot{\phi} p}}{=}, G=\frac{E}{2(1+v)}, \lambda=\frac{v E}{(1+v)(1-2 v)} J_{2}$ is the second stress invariant.

The values of coefficients are given in Table 4 .

\subsection{Thermal loading}

For obvious symmetrical consideration [31,32], only a quarter of the SPLASH specimen is meshed. For the SPLASH specimens, the quenched zone roughly corresponds to a $5 \times 10 \mathrm{~mm}^{2}$ rectangle. The thermal flux on the portion of the specimen that is in direct contact with air has been considered as constant and estimated from convection formulas as $\approx 5 \times 10^{3} \mathrm{~W} / \mathrm{m}^{2}$. The thermal flux on the quenched zone is assumed to have an elliptical spatial distribution, as presented on Fig. 6 .

The finite element calculations were made using CUB8 elements, cubic elements having eight nodes and eight Gauss points per element.

After computing up to three cycles, one can observe that the temperature cycle is stabilized. Fig. 7 shows that calculated and measured temperature in the centre of the quenched zone are in relatively good agreement. Experimental oscillations are due to electrical perturbations: heating results from a 1500-2000 A DC current.

The validity of the thermal loading calculations is also confirmed by the evolution of the computed temperature with depth, as shown on Fig. 8.

The thermal finite element calculations are carried out on half a FAT3D specimen only. Fig. 9 summarizes thermal modelling procedures. Heating is simulated with a convection coefficient $H_{\text {air }}$ between the specimen and the air heated $T_{\mathrm{c}}$ at the enforced furnace temperature, a radiation with a thermal emissivity coefficient $\varepsilon$ of the specimen and a temperature of the furnace radiation $T_{\text {ray }}$, ( $T_{\text {ray-int }}$ for the inner skin radiation). Cooling is simulated with: a convection coefficient $H_{\text {eau }}$ and the injected water temperature $T_{\mathrm{f}}$. Temperature evolution on the specimen also depends on the conduction coefficient $\mathrm{K}$.

Table 4

304L SPLASH and 316L FAT3D steel parameters identified for non-linear kinematic hardening laws

\begin{tabular}{llllllll}
\hline & $E(\mathrm{GPa})$ & $v$ & $\sigma_{\mathrm{y}}(\mathrm{MPa})$ & $a_{1}(\mathrm{GPa})$ & $a_{2}(\mathrm{GPa})$ & $c_{1}$ & $c_{2}$ \\
\hline 304L SPLASH & 175 & 0.3 & 102 & 114 & 0 & 532 & 0 \\
316L FAT3D & 177 & 0.3 & 140 & 114 & 310 & 1200 & 80 \\
\hline
\end{tabular}

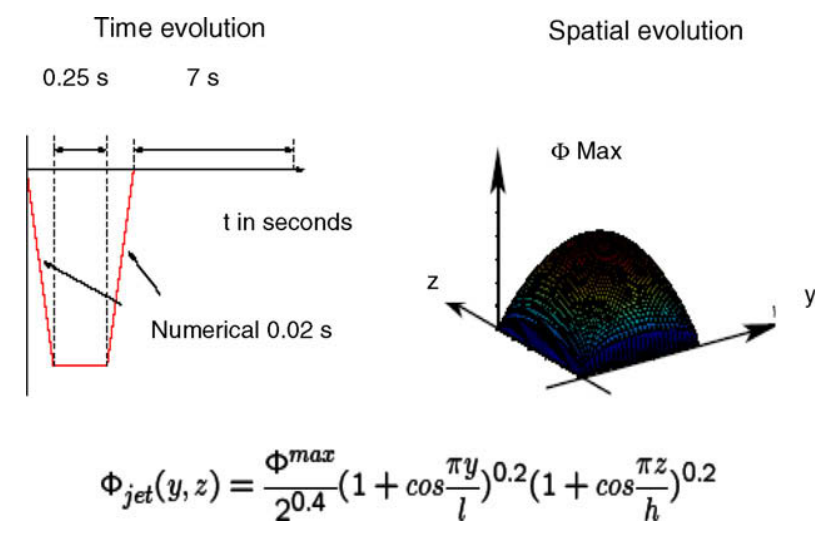

Fig. 6. Analytical description of the quenching water spray flux for the SPLASH specimen.

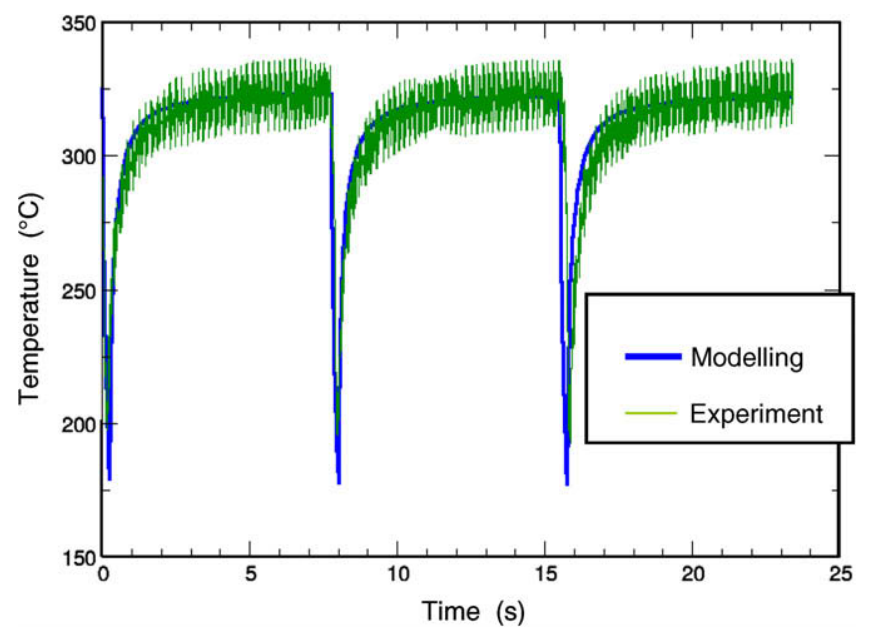

Fig. 7. Evolution of the temperature with time at the surface on SPLASH specimen Comparison between calculated and measured temperatures.

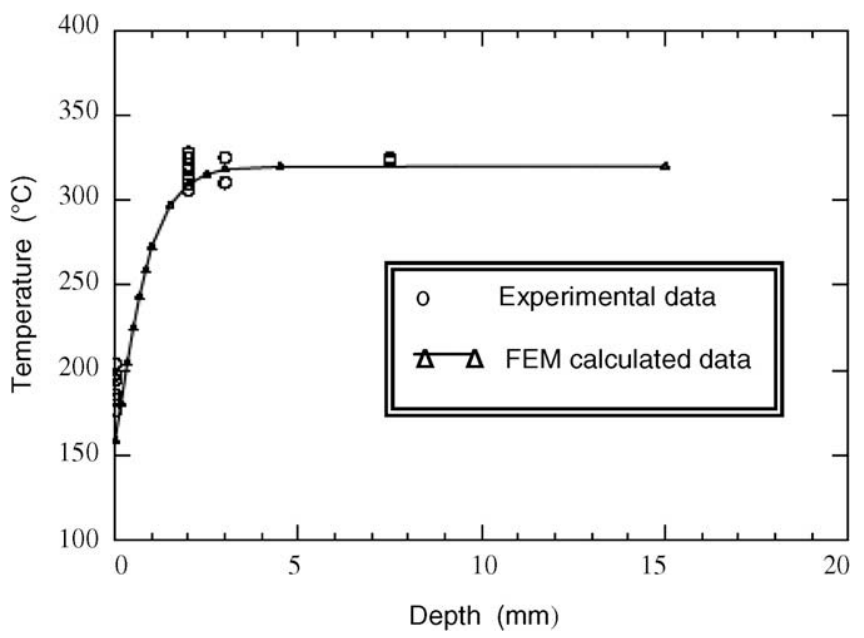

Fig. 8. Evolution of the temperature with depth on SPLASH specimen. Comparison between calculated and measured temperatures.

\subsection{Mechanical loading}

For both tests, we present pure elastic and elasto-plastic calculations in successive order. 
SPLASH: Selected boundary conditions are:

(i) No external strength applied to the specimen.

(ii) No displacement on axial and transversal surfaces.

The 3D FE elastic calculation results differ significantly from those deduced from an analytical 2D semi-wall modeling, they are significantly lower, as shown in Table 5.

Mechanical loading is not quite perfectly equibiaxial, since $\sigma_{y y}=0.7 \sigma_{z z}$. The difference between the two directions is ascribed to the larger specimen stiffness, along its length.

As $\sigma_{y y}=K \sigma_{z z}$ (with $K=0.7$ ), the triaxiality factor (TF) is simply given by:

$\mathrm{TF}=\frac{3 \sigma_{H}}{\sigma_{\mathrm{eq}}^{\mathrm{VM}}}=\frac{1+K}{\sqrt{1-K+K^{2}}}=1.91$

The ratio of distortion $\delta$ and $\gamma$ to a thermal shock on a free wall [30] is given by:

$\begin{aligned} \delta & =\frac{\Delta \varepsilon_{z z}-\Delta \varepsilon_{y y}}{\Delta \varepsilon_{z z}+\Delta \varepsilon_{y y}}=\frac{\Delta \sigma_{z z}-\Delta \sigma_{y y}}{\Delta \sigma_{z z}+\Delta \sigma_{y y}}\left(\frac{1+v}{1-v}\right) \approx 0.33 \gamma=\frac{\Delta \sigma_{z z}-\Delta \sigma_{y y}}{\Delta \sigma_{z z}+\Delta \sigma_{y y}} \\ & \approx 0.18\end{aligned}$

Consequently, the triaxiality factor ( $\mathrm{TF}=1.91$ ) is close to 2 , which corresponds to a perfectly equibiaxial state.

3D FE elasto-plastic calculations clearly confirm such behaviour. The mechanical response is biaxial at the surface, as illustrated for stress components in Fig. 10. As for elastic calculation, $\sigma_{z z}$ oriented along the length is higher than $\sigma_{y y}$. Besides, plasticity is also higher along the specimen's width. Calculated values of $\sigma_{x x}$ are negligible compared to $\sigma_{y y}$ and $\sigma_{z z}$.

The duration of the cycle portion corresponding to quenching is $0.25 \mathrm{~s}$. During that stage, the surface is under tension. After the end of quenching, the surface is under compression.

Table 6 displays values of equivalent stress range, hydrostatic stress range, mean hydrostatic stress, equivalent elastic strain range, equivalent plastic strain range, and equivalent total strain range for different temperature variations.

Fig. 11 confirms the quasi-proportionality of the mechanical loading, since $\sigma_{y y} \approx 0.76 \sigma_{z z}$ (full line) and $\sigma_{x x}=0$ in the surface. The absolute value of the triaxiality factor is 1.95 (see Eq. (2)). It is close to the one previously estimated from elastic FE calculations.

FAT3D: The boundary conditions are the upper specimen surface blocked in the $z$-direction, to reproduce the effect of the hold-
Table 5

Elastic calculations on SPLASH tests

\begin{tabular}{lll}
\hline$\Delta T\left({ }^{\circ} \mathrm{C}\right)$ & $\Delta \sigma_{\text {eq }}(\mathrm{MPa})$ FEM calculations & $\Delta \sigma_{\text {eq }}(\mathrm{MPa}) 2 \mathrm{D}$ semi-wall \\
\hline 125 & 364 & 541 \\
150 & 495 & 649 \\
200 & 582 & 869
\end{tabular}

$\overline{\text { Von Mises equivalent stresses calculated with 3D finite element and 2D semi-wall }}$ analytical modelling.

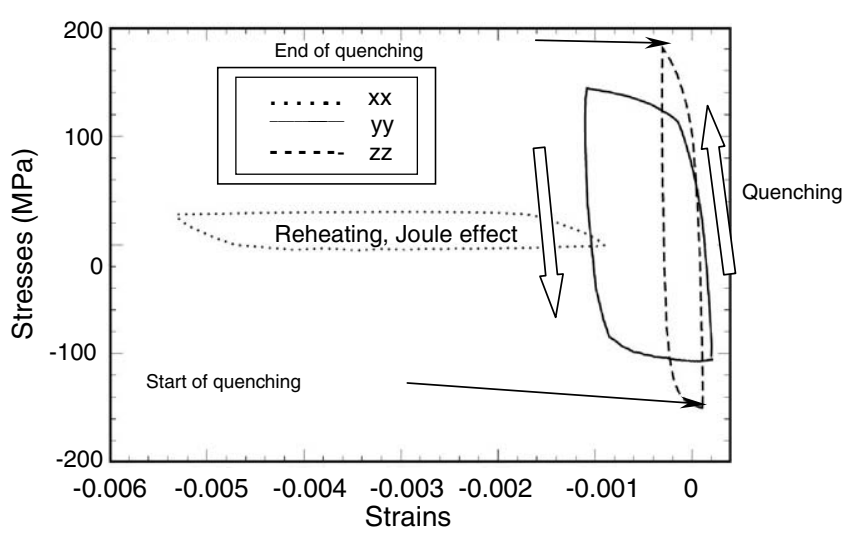

Fig. 10. Elasto-plastic calculations on SPLASH tests: stress-strain evolutions at the center of the quenched surface for $\Delta T=150^{\circ} \mathrm{C}$. Axis $x, y, z$ are respectively oriented on the thickness, width and length specimen directions.

Table 6

Elasto-plastic calculations on SPLASH tests

\begin{tabular}{lllllllll}
\hline $\begin{array}{l}\Delta T \\
\left({ }^{\circ} \mathrm{C}\right)\end{array}$ & $\begin{array}{l}\Delta \sigma_{\mathrm{eq}} \\
(\mathrm{MPa})\end{array}$ & $\begin{array}{l}\Delta \sigma_{y y} \\
(\mathrm{MPa})\end{array}$ & $\begin{array}{l}\Delta \sigma_{\mathrm{zz}} \\
(\mathrm{MPa})\end{array}$ & $\begin{array}{l}\Delta \sigma_{\mathrm{h}} \\
(\mathrm{MPa})\end{array}$ & $\begin{array}{l}\sigma_{\mathrm{hmean}} \\
(\mathrm{MPa})\end{array}$ & $\begin{array}{l}\Delta \varepsilon_{\text {eleq }} \\
(\%)\end{array}$ & $\begin{array}{l}\Delta \varepsilon_{\text {peq }} \\
(\%)\end{array}$ & $\begin{array}{l}\Delta \varepsilon_{\text {eq }} \\
(\%)\end{array}$ \\
\hline 125 & 248 & 231 & 302 & 184 & 16 & 0.14 & 0.07 & 0.21 \\
150 & 270 & 252 & 330 & 204 & 16 & 0.15 & 0.11 & 0.26 \\
200 & 321 & 298 & 395 & 249 & 18.5 & 0.18 & 0.21 & 0.39 \\
\hline
\end{tabular}

Main stress and strain values.

ing system (see Fig. 4), and a fixed node impedes motion of the rigid body.

On SPLASH, maximum loading is located at the centre of the quenched zone, whereas on $F A T 3 D$, it is located in the top part of

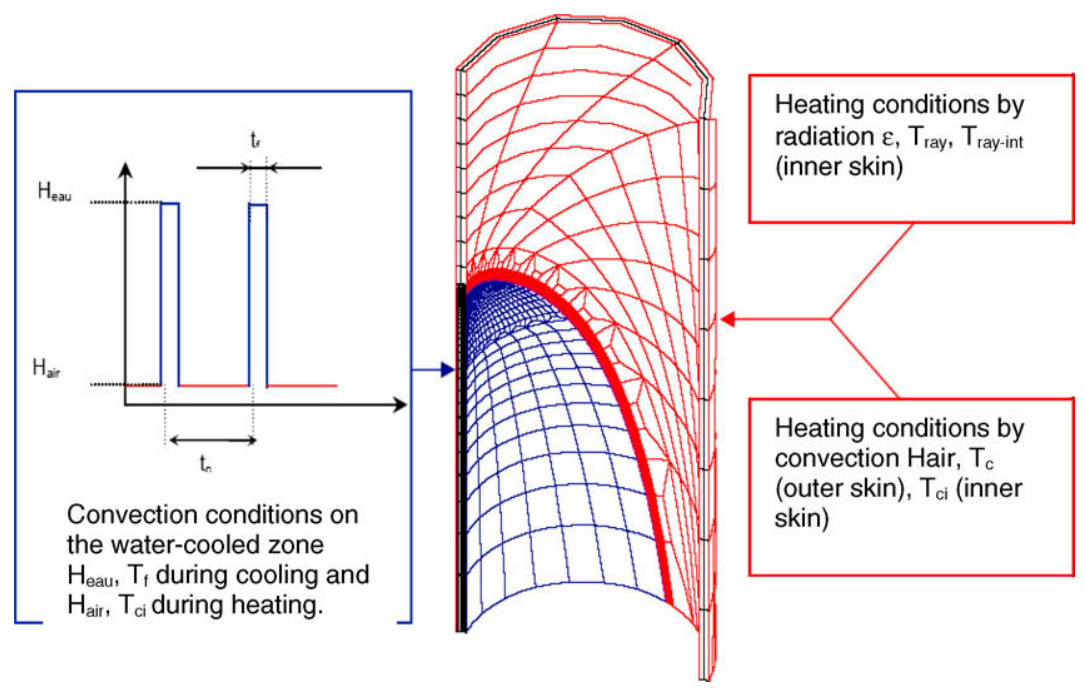

Fig. 9. $F A T 3 D$ thermal modelling-meshing and test principle. 


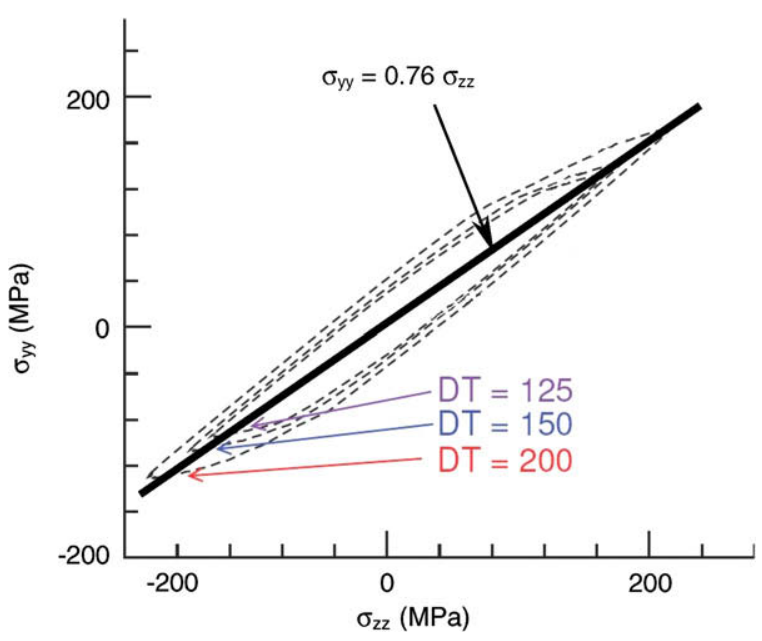

Fig. 11. Elasto-plastic calculations on SPLASH tests: evolution of $\sigma_{y y}$ versus $\sigma_{z z}$. The dotted curves correspond to the three thermal conditions used on SPLASH: $\mathrm{DT}=125,150$ and $200^{\circ} \mathrm{C}$. The full line corresponds to a linear fitting.

Table 7

Elastic calculations on FAT3D tests

\begin{tabular}{llll}
\hline Test & FAT3D-1 & FAT3D-2 & FAT3D-3 \\
\hline$\Delta \sigma_{\text {eq }}(\mathrm{MPa})$ & 1171 & 829 & 705 \\
$\Delta \varepsilon_{\mathrm{eq}}(\%)$ & 0.57 & 0.41 & 0.35 \\
$\Delta \sigma_{\mathrm{zz}} / \Delta \sigma_{\theta \theta}$ & 0.76 & 0.71 & 0.68 \\
$\mathrm{TF}$ & 1.95 & 1.92 & 1.90 \\
$\gamma$ & 0.14 & 0.17 & 0.19 \\
\hline
\end{tabular}

Stresses and strains calculated with 3D finite element.

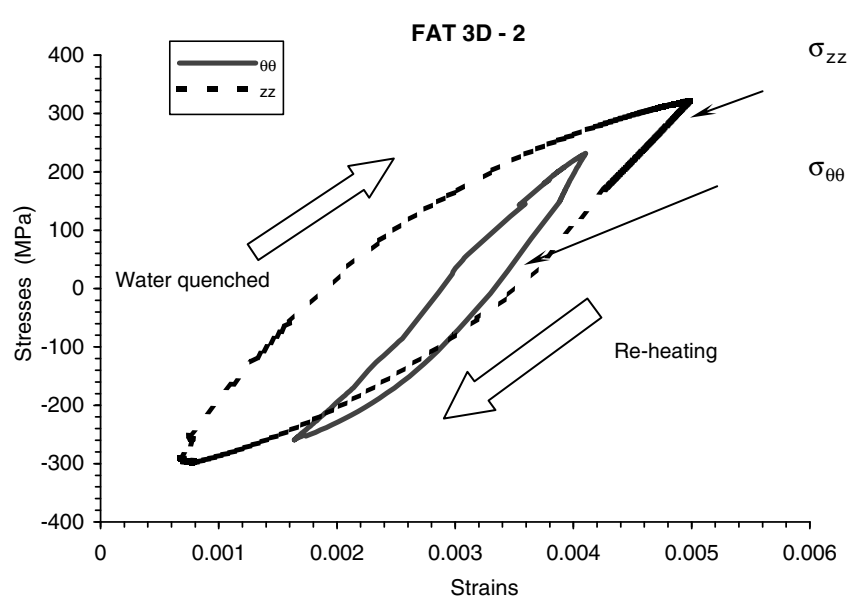

Fig. 12. Elasto-plastic calculations on FAT3D tests: stress-strain evolutions at the top part of the parabolic shape of the quenched zone for the FAT3D-2 test (see Fig. 4). Maximum tension corresponds to the end of water quenching, stress state is biaxial $\left(\Delta \sigma_{z z}=0.79 \Delta \sigma_{\theta \theta}\right)$, triaxiality factor TF is close to $2(\mathrm{TF}=1.94)$. Axis $r, \theta, z$ are respectively oriented on the thickness, angular and longitudinal specimen directions.

the parabolic shape of the quenched zone. Therefore, in order to investigate crack initiation, the mechanical values presented hereafter are taken from that location.

3D FE elastic calculations show values of $\Delta \sigma_{z z} / \Delta \sigma_{\theta \theta}$ about 0.7 , TF close to $2(1.90 \leqslant \mathrm{TF} \leqslant 1.95)$ and slight $\delta$ factors $(0.25 \leqslant \delta \leqslant 0.35)$. Values are summarised hereafter in Table 7.

As for SPLASH, 3D FE elasto-plastic calculations on FAT3D tests confirm a biaxial mechanical response on the surface, as illustrated in Fig. 12.
Table 8

Elasto-plastic calculations on FAT3D tests

\begin{tabular}{lllllllll}
\hline Test & $\begin{array}{l}\Delta \sigma_{\mathrm{eq}} \\
(\mathrm{MPa})\end{array}$ & $\begin{array}{l}\Delta \sigma_{\theta \theta} \\
(\mathrm{MPa})\end{array}$ & $\begin{array}{l}\Delta \sigma \mathrm{S}_{\mathrm{zz}} \\
(\mathrm{MPa})\end{array}$ & $\begin{array}{l}\Delta \sigma_{\mathrm{h}} \\
(\mathrm{MPa})\end{array}$ & $\begin{array}{l}\sigma_{\mathrm{hmmean}} \\
(\mathrm{MPa})\end{array}$ & $\begin{array}{l}\Delta \varepsilon_{\mathrm{el}} \\
(\%)\end{array}$ & $\begin{array}{l}\Delta \varepsilon_{\mathrm{pl}} \\
(\%)\end{array}$ & $\begin{array}{l}\Delta \varepsilon_{\text {teq }} \\
(\%)\end{array}$ \\
\hline FAT3D-1 & 643 & 699 & 566 & 408 & 3 & 0.32 & 0.45 & 0.77 \\
FAT3D-2 & 562 & 615 & 486 & 351 & 9 & 0.28 & 0.23 & 0.51 \\
FAT3D-3 & 512 & 512 & 408 & 323 & 16 & 0.25 & 0.17 & 0.42 \\
\hline
\end{tabular}

Stresses and strains calculated with 3D finite element.

Table 8 gathers values of equivalent stress range, hydrostatic stress range, mean hydrostatic stress, equivalent elastic strain range, equivalent plastic strain range, and equivalent total strain range, for the three tests.

Fig. 13 confirms the quasi-proportionality of the mechanical loading. TF values are close to those previously estimated from elastic FE calculations.

For both tests, the stress state is not quite perfectly biaxial in surface, since the two principal stresses differ significantly. However, TF values are ever close to two.

\section{Fatigue analysis with the French RCC-MR design code}

In order to compare thermal fatigue and isothermal fatigue results, a simplified methodology is applied. Plastic strain can be directly estimated from the strain calculated by assuming a pure elastic behaviour. It is based on the correction of the Poisson effect in the elastic analysis of low cycle fatigue [23,29,30]. More details of methodology are given in Appendix A.

When thermal fatigue loading corresponds to a perfect biaxial state. It thus undergoes a fictitious equivalent elastic stress range and a corresponding equivalent strain range respectively defined as:

$\Delta \varepsilon_{\mathrm{eq}}=K_{v \mathrm{~b}} \Delta \varepsilon_{\mathrm{eq}}$

where $\Delta \varepsilon_{\mathrm{eq}_{\mathrm{e}}}$ is the elastic strain range as previously deduced and $K_{v \mathrm{~b}}$ is a coefficient obtained from the stabilized stress-strain loop.

For a perfect biaxial thermal shock, values of $K_{v \mathrm{~b}}$ range between 1 for an elastic behaviour and 1.61 for a full plastic behaviour.

Let us note that the true value of $K_{v c}$ is different (lower) when the stress state is not quite perfectly equibiaxial (see Appendix A):

$K_{v c}=K_{v \mathrm{~b}}\left(\frac{1+3 \frac{\gamma^{2}}{K_{v \mathrm{~b}}^{2}}}{1+3 \gamma^{2}}\right) \quad$ with $\gamma=\frac{\Delta \sigma_{z z}-\Delta \sigma_{y y}}{\Delta \sigma_{z z}+\Delta \sigma_{y y}}$

As the distortion coefficient $\gamma$ from a perfect equibiaxiality state is ever lower than 0.20 (SPLASH and FAT3D tests), the difference between $K_{v \mathrm{c}}$ and $K_{v \mathrm{~b}}$ cannot exceed $7 \%$ :

As : $1 \leqslant K_{v \mathrm{~b}} \leqslant 1.61 \quad 0.93 \leqslant \frac{K_{v c}}{K_{v 3}} \leqslant 1$

The hypothesis of a perfect biaxial mechanical loading $(\gamma=0)$ generates conservative strain values for a structural component.

Values of the $K_{v \mathrm{~b}}$ coefficients have been provided in Appendix 3S of the RCC-MR code (only for perfect biaxial loading). Moreover, they have been reported only for the 316L steel. For 304L steel, one proposes to estimate $K_{v \mathrm{~b}}$ coefficients from the cyclic stabilized curve using the methodology presented in Appendix A. Values of $K_{v c}$ are also given. Values of strains assuming perfect biaxiality $\left(\Delta \varepsilon_{\mathrm{tb}}\right)$ and corrected strains $\left(\Delta \varepsilon_{\mathrm{tc}}\right)$ are simply deduced from $\mathrm{K}_{v \mathrm{~b}}$ and $\mathrm{K}_{v \mathrm{c}}$.

In Table 9, estimated strains on SPLASH are gathered. In Fig. 14, we compare equivalent strains $\left(\Delta \varepsilon_{\mathrm{tc}}\right)$ determined for $304 \mathrm{~L}$ steel with LCF data obtained with specimens taken from the same plate, at 165 and $320^{\circ} \mathrm{C}$ (maximum and medium temperatures of the thermal cycle). In all instances, thermal fatigue results are 


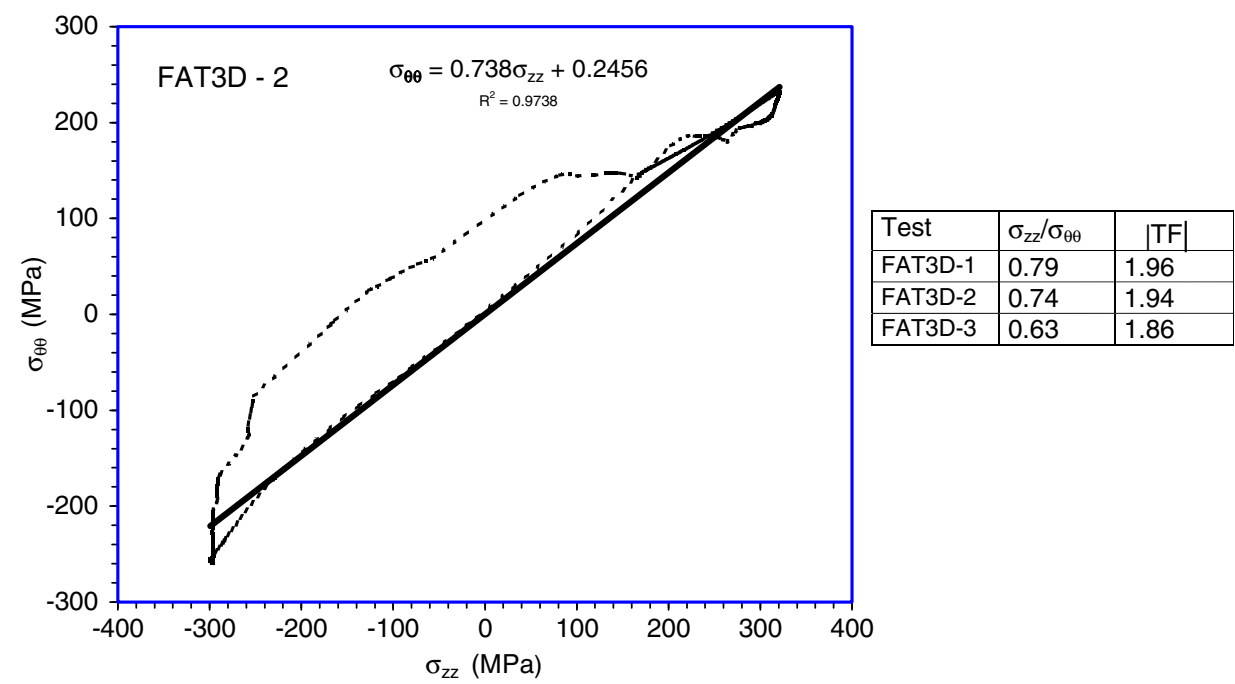

Fig. 13. Elasto-plastic calculations on FAT3D tests: evolution of $\sigma_{y y}$ versus $\sigma_{z z}$ and triaxiality factor TF.

Table 9

RCC-MR methodology, application to the SPLASH tests

\begin{tabular}{lllllllll}
\hline Steel & $\Delta T\left({ }^{\circ} \mathrm{C}\right)$ & $\begin{array}{l}T_{\max } \\
\left({ }^{\circ} \mathrm{C}\right)\end{array}$ & $\begin{array}{l}\Delta \sigma_{\mathrm{e}} \\
(\mathrm{MPa})\end{array}$ & $K_{v \mathrm{~b}}$ & $\gamma$ & $K_{v \mathrm{c}}$ & $\Delta \varepsilon_{\mathrm{tb}}(\%)$ & $\Delta \varepsilon_{\mathrm{tc}}(\%)$ \\
\hline $304 \mathrm{~L}$ & 125 & 320 & 364 & 1.17 & 0.18 & 1.14 & 0.20 & 0.20 \\
304L & 150 & 320 & 495 & 1.22 & & 1.18 & 0.30 & 0.29 \\
304L & 200 & 320 & 582 & 1.24 & & 1.20 & 0.35 & 0.34 \\
$316 \mathrm{~L}(\mathrm{~N})$ & 150 & 320 & 495 & 1.19 & & 1.15 & 0.29 & 0.28 \\
\hline
\end{tabular}

significantly lower than uniaxial results. However, such a comparison remains questionable, since the number of cycles required to initiate cracks in thermal fatigue conditions are compared to the number of cycles $N_{\mathrm{F}}$, which corresponds roughly to a 3-mm crack length on a cylindrical LCF specimen.

In this framework, LCF curves are modified to estimate the number of cycles required to initiate a $50-\mu \mathrm{m}$ crack (LCF dottedline on Fig. 14). Such a correction was proposed by [33]:

$N_{i}(50 \mu \mathrm{m})=N_{\mathrm{F}}-12 N_{\mathrm{F}}^{0.62}+0.226 N_{\mathrm{F}}^{0.90}+185$ for $20 \leqslant T \leqslant 600{ }^{\circ} \mathrm{C}$

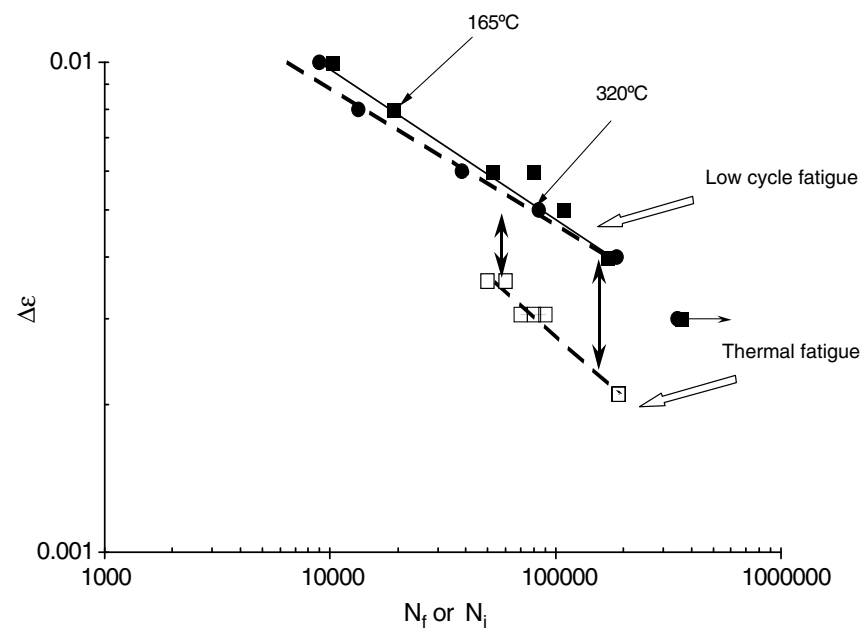

Fig. 14. RCC-MR analysis on SPLASH tests. Comparison between LCF and TF performed on a $304 \mathrm{~L}$ steel of the same plate. For LCF tests, dotted-line corresponds to crack initiation estimated from Eq. (6).
Table 10

RCC-MR methodology, application to the FAT3D tests

\begin{tabular}{llllllll}
\hline Steel & Test & $\Delta \sigma_{\mathrm{e}}(\mathrm{MPa})$ & $K_{v \mathrm{~b}}$ & $\gamma$ & $K_{v \mathrm{c}}$ & $\Delta \varepsilon_{\mathrm{tb}}(\%)$ & $\Delta \varepsilon_{\mathrm{tc}}(\%)$ \\
\hline \multirow{2}{*}{$316 \mathrm{~L}$} & FAT3D-1 & 1171 & 1.28 & 0.14 & 1.25 & 0.74 & 0.72 \\
& FAT3D-2 & 829 & 1.21 & 0.17 & 1.18 & 0.49 & 0.48 \\
& FAT3D-3 & 705 & 1.17 & 0.19 & 1.14 & 0.40 & 0.39
\end{tabular}

Then, the number of cycles required to initiate cracking is compared under both conditions. It clearly confirms that thermal fatigue is more damaging than uniaxial fatigue.

In Table 10, estimated strains on FAT3D are gathered. As for SPLASH tests, Fig. 15 shows that FAT3D results are below LCF results obtained using specimens taken from the same 316L plate.

In all the cases examined, RCC-MR methodology does not give efficient estimations of crack initiation under thermal fatigue. One proposes now to investigate the difference between the two loading conditions, using more accurate calculations.

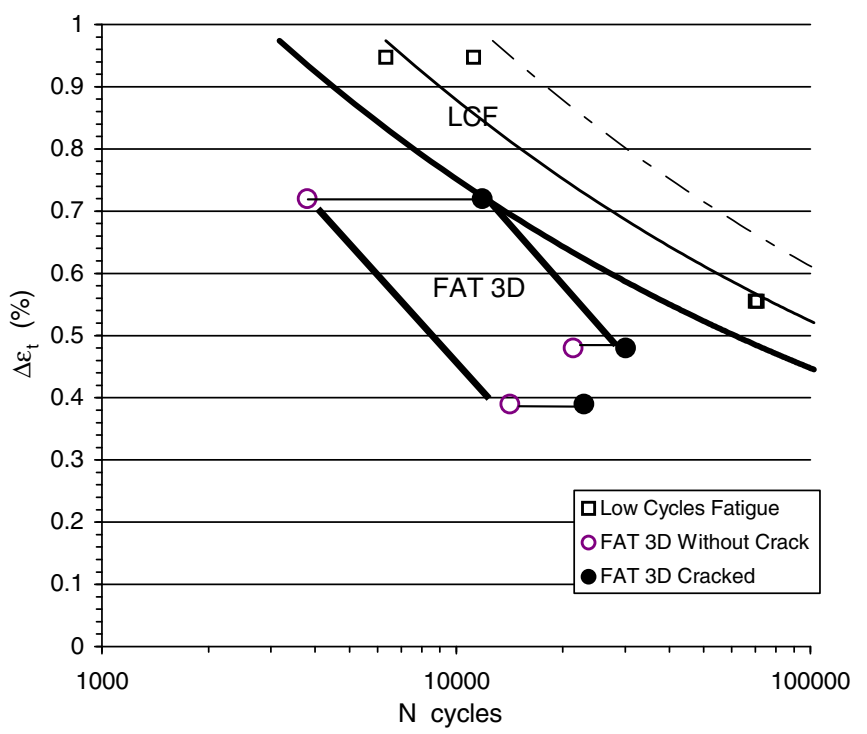

Fig. 15. RCC-MR analysis on FAT3D tests. Comparison between LCF and TF performed on $316 \mathrm{~L}$ steel specimens from the same plate. LCF full line corresponds to $N_{\mathrm{R}} / 2$ curve at room temperature (see Fig. 5). 


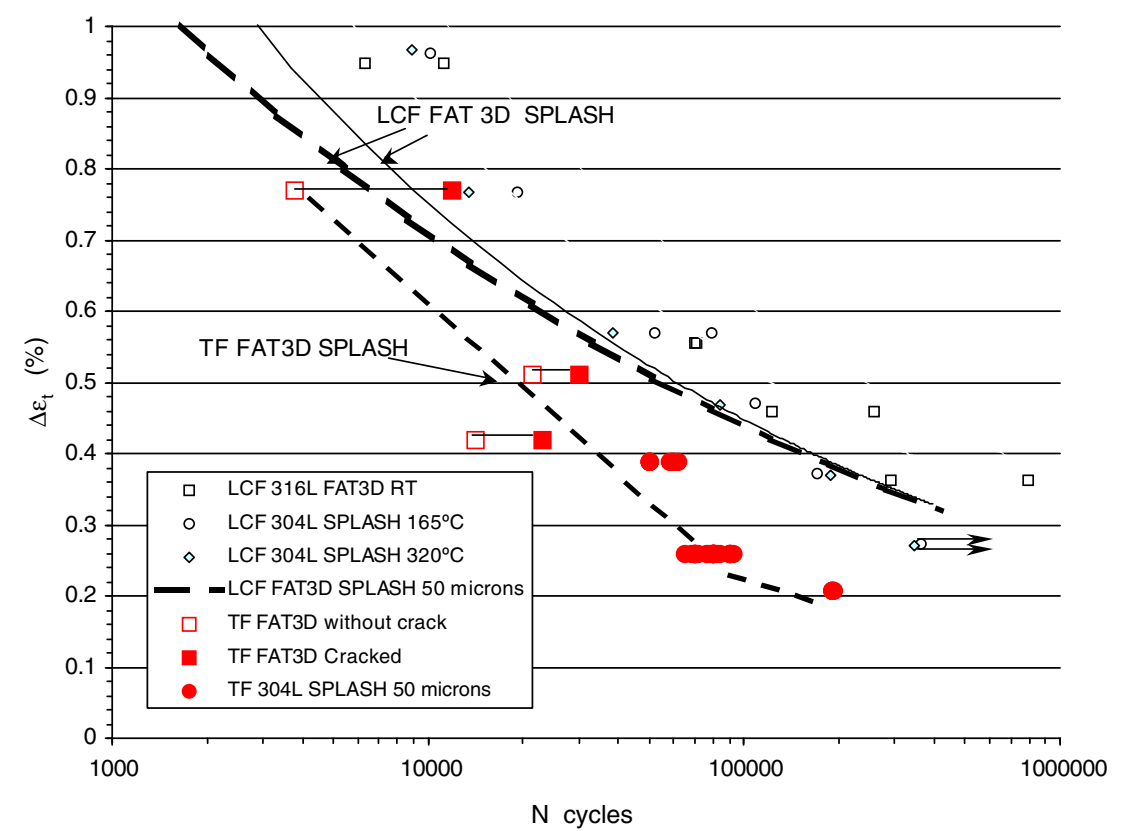

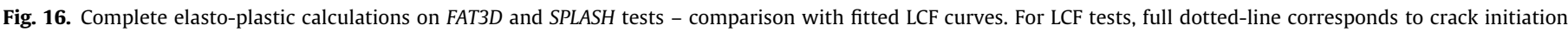
estimated from Eq. (6).

\section{Fatigue analysis using elasto-plastic calculations}

Fig. 16 compares thermal fatigue estimations, deduced on both facilities from elasto-plastic calculations (Section 4.3), with the uniaxial low cycle fatigue curves. The LCF dotted-line curve represents the fatigue life. It corresponds approximately to a 3-mm crack. It is built from the $\left(N_{\mathrm{F}} / 2-\Delta \varepsilon_{\mathrm{t}}\right)$ curve obtained on $316 \mathrm{~L}$ steel at room temperature and the $\left(N_{\mathrm{F}}-\Delta \varepsilon_{\mathrm{t}}\right)$ curves obtained on $304 \mathrm{~L}$ steel at temperatures of 165 and $320^{\circ} \mathrm{C}$. The LCF full line represents the number of cycles required to initiate a $50-\mu \mathrm{m}$ long crack. It is simply deduced from the LCF dotted-line curve, using Eq. (6) [33]. One FAT3D crack point (full symbol) would seem to be slightly above the LCF full curve. However, this corresponds to a very large crack (30-mm length) and for the same test, the FAT3D uncracked data (open symbol) is significantly lower than the LCF full curve.

The previously obtained trend is clearly confirmed [34]. Indeed, elasto-plastic calculations do not accurately estimate thermal fatigue life. Thermal fatigue analysis based on equivalent strain (related to the second invariant), is therefore insufficient.

\section{Some comments}

(1) The difference between thermal fatigue and uniaxial low cycle fatigue is not due to any known micro-structural effects. Temperatures are not high enough to lead to a significant vacancy over-saturation, inducing dislocation climb [35]. Transmission electron microscopy (TEM) observations provide insights into the slip mechanisms [35], which appear to be standard. In addition, temperature variations on surface are limited and no phase transformation can occur. Cyclic plasticity could induce martensitic transformation. However, such martensite phase was observed only when plastic strain is higher than $0.6 \%$ [36], whereas plastic strain is ever lower than $0.2 \%$ on SPLASH specimens. Consequently, only a weak pure thermal would seem to be present for our used test conditions. Nevertheless, to reach a definitive conclusion, a comparison with "out of phase" thermo-mechanical fatigue tests (TMF) [37] could be also made, since TMF specimens are submitted to both temperature variation and uniaxial loading.

(2) An impact of frequency on fatigue behaviour can be also questionable since SPLASH tests are performed with a frequency of $4 \mathrm{~Hz}$ (water spray applied in $0.25 \mathrm{~s}$ ), whereas LCF tests are performed with a frequency $\sim 0.1 \mathrm{~Hz}$. As it was shown at "Ecole Supérieure des Mines de Paris" [38], viscous effects are negligible in the temperature range used for these tests (see Appendix B).

(3) An environmental effect may be present, due to the water sprays (water + air) used for quenching on SPLASH and $F A T 3 D$. Such effect would be significant even for very weak oxygen content in water for austenitic stainless steels [3941]. The effect of reactor coolant environments on fatigue life has also been accounted for in terms of a fatigue life correction $F_{\text {en }}$. However, these effects seem to be limited to low strain rates $(\dot{\varepsilon} \cdot \leqslant 0.4 \% / s)$. Moreover, it is often associated with (at least) partial inter-granular fracture mode. Moreover, the environmental effect seems to mainly impact the crack propagation stage.

In the case of the SPLASH tests, a high strain rate is obtained especially during the tensile phase (which is the most critical for fatigue damage). For example, a strain range of $0.26 \%$ is obtained in the $0.25 \mathrm{~s}$ quenching stage (Table 6). This roughly corresponds to a strain rate of $1 \% \mathrm{~s}^{-1}(0.26 \% /$ $0.25 \mathrm{~s}$ ). Furthermore, no inter-granular fracture mode has been evidenced using a scanning electron microscope (SEM) on fracture surface.

In the case of the FAT3D tests, the strain rate is significantly lower. For example, a strain range of $0.41 \%$ is obtained in the $15 \mathrm{~s}$ cooling. This roughly corresponds to a strain rate of $0.03 \% \mathrm{~s}^{-1}(0.41 \% / 15 \mathrm{~s})$. However, as for SPLASH, SEM observations on the FAT3D-1 test do not show any inter-granular fracture mode.

Although complementary investigations are needed to reach definitive conclusions, the effect of water would seem to be limited, especially for the SPLASH tests. In this case, the strain rate is high, and only crack initiation is considered. 


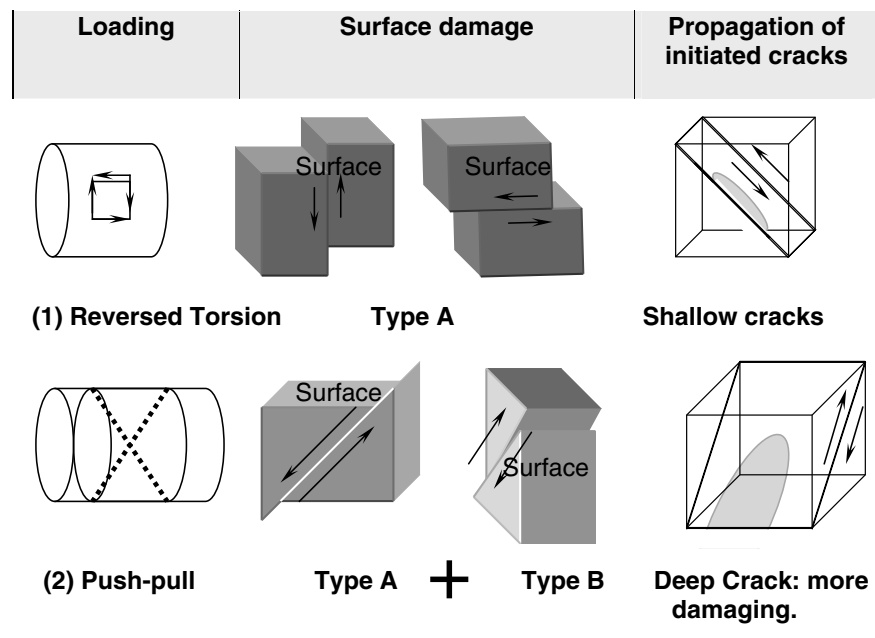

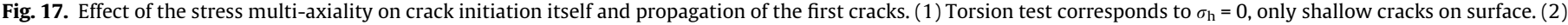
Push-pull test corresponds to positive hydrostatic stress $\left(\sigma_{\mathrm{hmax}}=\sigma_{\max } / 3\right)$, stair displacement on surface and deep cracks, which are more damaging.

(4) The main experimental problem comes from temperature measurements and the determination of the thermal loading. Temperature variations with time were deduced from thermocouple signal monitoring. Using thermocouple lead to some imprecision especially in surface, since thermocouple soldering can disturb temperature measurements themselves. In addition, these measurements have a local character too. Therefore, in order to improve thermal measurements and obtain complete thermal maps, an infrared camera was used on the SPLASH facility. Another experimental difficulty may be due to modification (as oxidation) of the quenched surface during cycling. That may lead to a substantial modification of the thermal parameters, such as the thermal emissivity.

Testing quasi-structural specimens (as SPLASH or FAT3D) is assuredly an important step for understanding thermal fatigue damage. In the next step, the CEA thermal fatigue programme includes tests on a representative structure, representative of RHRS of PWR (FATHER programme), so as to achieve the thermo-hydraulic, mechanical loadings that are representative of the in-service conditions [42], and to detect the potential resulting damage. However, simpler tests are also needed to determine the general evolutions. In that framework, performing isothermal perfect biaxial tests, or/and TMF tests, environmental fatigue tests would be a clear advantage.

(5) The effect of multiaxial stress on fatigue damage is now well investigated. Many criteria have been proposed [43-46] for industrial applications, as in the car industry, the railway, etc.
The first effect of stress multiaxiality is the modification of the crack initiation stage itself $[16,47]$. In all the cases, cracks are initiated following shearing stress planes. However, an increase in hydrostatic stress (the first invariant of the stress tensor), leads to a substantial micro-mechanism change: low hydrostatic stresses lead to the development of shallow cracks parallel to the surface (Type A damage), whereas high hydrostatic stresses leads instead to the development of surface steps and deeper cracks (Type B damage), which are obviously more damaging (Fig. 17). More precisely, it was shown that torsion mainly corresponds to Type A damage, push-pull tests to a mixing of Type A and Type B damage, and perfect biaxiality, to predominantly Type B damage. Therefore, the number of cycles required to initiate a crack is significantly higher in cyclic torsion $\left(\sigma_{\mathrm{H}}=0\right)$ than in cyclic tension $\left(\sigma_{\mathrm{H}}=\sigma_{\mathrm{a}} / 3\right)$, and higher in tension than in cyclic perfect biaxial loading $\left(\sigma_{\mathrm{H}}=2 \sigma_{\mathrm{a}} / 3\right)$.

The second effect is linked to crack opening. An increase in the hydrostatic stress leads to an increase in pressure on the crack lips. That impedes crack closure during unloading (Fig. 18). This effect also promotes micro-crack coalescence or micro-voids ahead of the main propagating crack.

Moreover, a biaxial loading activates more slip systems (Fig. 19) [35], which can also promote premature crack initiation.

Thermal fatigue loading in-service is multiaxial: loading is proportional and biaxial. However, another important factor is the possible superposition of a mean static stress during cycling. This loading may result from water pressure in the lines. In nominal operating conditions, the pressure in the
(1) Torsion test

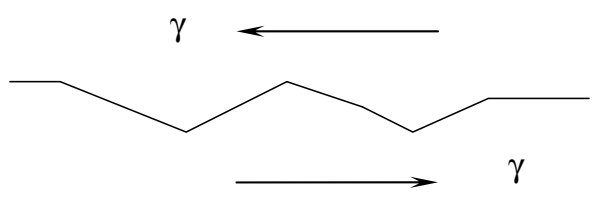

(2) Push-pull test, tensile phase

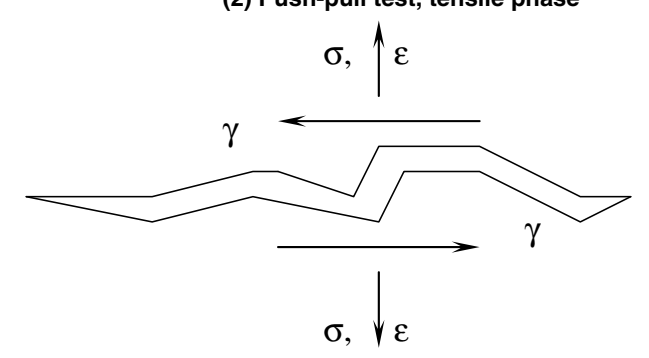

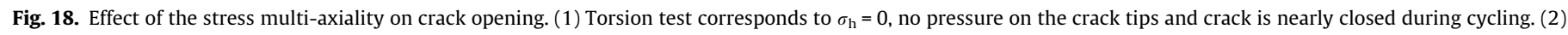
Push-pull test corresponds to positive hydrostatic stress $\left(\sigma_{\mathrm{hmax}}=\sigma_{\max } / 3\right)$, crack may be opened during a part of tensile phase. 


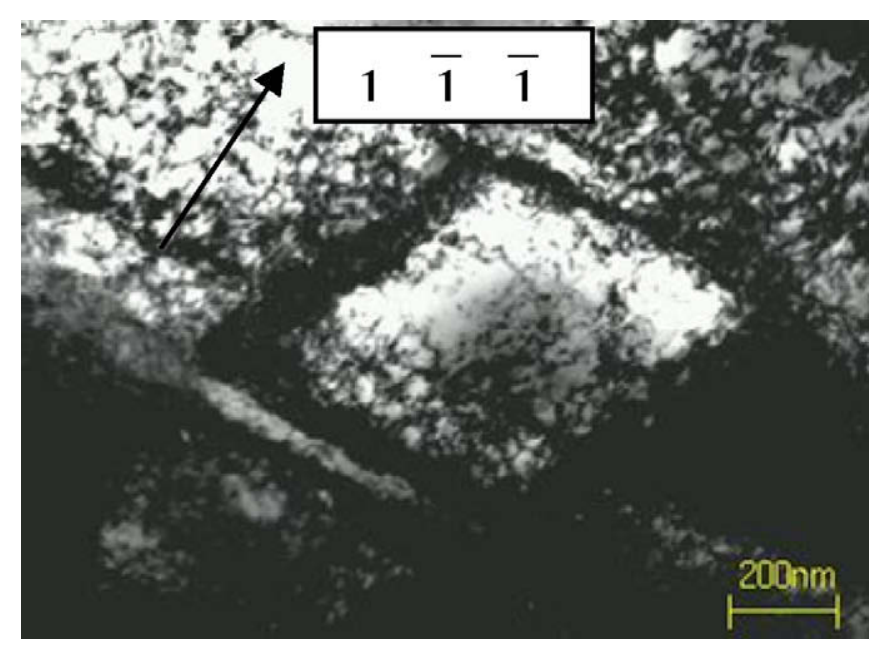

Fig. 19. Effect of the stress multi-axiality on slip systems. Activation of two intense slip systems when loading is biaxial, whereas one system would be active for comparable conditions when loading is uniaxial (same equivalent stress $\sigma_{\mathrm{eq}}$ ).

primary cooling system is about 155 bars. In the RHRS, the pressure is $30-40$ bars. A simple calculation adapted to a thin-walled pipe gives a mean stress of $40 \mathrm{MPa}$. Pressureinduced stress may be added with stresses due to the component's own weight, as well as to residual stresses resulting from machining.

Although pure thermal effect seems to be weak (item 1 ), one intends to investigate about TMF on austenitic stainless steels in a next step (Part II). One proposes to apply some multiaxial fatigue criteria on the CEA thermal fatigue tests. With the respect to the main characteristics of multiaxial fatigue damage, the relevance of the investigation approaches proposed in the literature and existing criteria will be investigated (bibliographic research). The purpose of this task is to select those criteria which would seem to be the most efficient to estimate the thermal fatigue crack initiation for austenitic stainless steels. Such investigation could also be used to develop new multiaxial fatigue criteria, especially for intermediate and high numbers of cycle fatigue regimes.

\section{Conclusion}

In order to deduce the thermo-mechanical loading state in quasi-structural specimens, two uncoupled computations have been performed: first a thermal analysis and then, a mechanical analysis with the previously computed temperature field as input parameters. The estimated temperature field is validated by comparison with measurements. All computations have been carried out with the object-oriented finite element software CAST3M.

All analysed tests clearly show that crack initiation in thermal fatigue occurs before crack initiation under uniaxial isothermal fatigue. On both SPALSH and FAT3D tests, thermal fatigue is always the most damaging case. Let us note that the same trends are obtained with a 2D specimen and with a "structure" 3D specimen. On both thermal fatigue specimens, a biaxial stress state is obtained, which corresponds to an increase in hydrostatic stress. Detrimental effects of hydrostatic stress (first tensor invariant) for initiation itself, and for crack propagation in the first stages as well, have been evidenced before.

The enhanced damaging effect probably results, for a significant part, from a pure mechanical source. However, additional mechanical tests and investigations are needed, in order to achieve meaningful conclusions on these points. A Part II accompanying paper will be dedicated to investigate accurately on multiaxial effect, and to improve thus estimation of crack initiation under thermal fatigue.

\section{Acknowledgement}

This work was initiated and supported by the French institute of protection and nuclear safety IRSN.

\section{Appendix A. Methodology based on correction of the Poisson effect in the elastic analysis}

A.1. Application to a thermal shock on a free wall and main steps of the RCC-MR method

Thermal shock on a free wall corresponds to a perfect biaxial stress state.

In terms of elasticity, strains and stresses are related by the Hooke's equations including Young's modulus $E$ and Poisson's coefficient $v$. When significant plasticity occurs, analogous equations can be verified with changing $E$ by the secant modulus $E_{s}$, and $v$ by the effective Poisson's coefficient $v_{\mathrm{s}}$ (Fig. A1).

Before examining the perfect biaxial case, the uniaxial case is considered.

(1) Uniaxial case, $z$ represents the tension axis

The strain tensor may be decomposed as the sum of an elastic part and plastic part as:

$$
\begin{aligned}
\underline{\underline{\Delta \varepsilon_{\mathrm{t}}}}= & \underline{\underline{\Delta \varepsilon_{\mathrm{e}}}}+\underline{\underline{\Delta \varepsilon_{\mathrm{p}}}}=\left(\begin{array}{ccc}
-\bar{v} \frac{\Delta \sigma}{E_{\mathrm{s}}} & 0 & 0 \\
0 & -\bar{v} \frac{\Delta \sigma}{E_{\mathrm{s}}} & 0 \\
0 & 0 & \frac{\Delta \sigma}{E_{\mathrm{s}}}
\end{array}\right)=\left(\begin{array}{ccc}
-v \frac{\Delta \sigma}{E} & 0 & 0 \\
0 & -v \frac{\Delta \sigma}{E} & 0 \\
0 & 0 & \frac{\Delta \sigma}{E}
\end{array}\right) \\
& +\left(\begin{array}{ccc}
-\frac{1}{2} \Delta \varepsilon_{\mathrm{p}} & 0 & 0 \\
0 & -\frac{1}{2} \Delta \varepsilon_{\mathrm{p}} & 0 \\
0 & 0 & \Delta \varepsilon_{\mathrm{p}}
\end{array}\right)
\end{aligned}
$$

We obtain:

$\bar{v}=v \frac{E_{\mathrm{s}}}{E}+\frac{1}{2}\left(1-\frac{E_{\mathrm{s}}}{E}\right)$

Thereafter, coefficients $E_{\mathrm{s}}$ and $v_{\mathrm{s}}$ are directly determined from the experimentally stabilized cyclic curve obtained with push-pull tests on the same material.

(2) Perfect biaxial case, $y, z$-axis are placed on the surface

$$
\begin{aligned}
\underline{\underline{\Delta \varepsilon_{\mathrm{t}}}} & =\underline{\underline{\Delta \varepsilon_{\mathrm{e}}}}+\underline{\underline{\Delta \varepsilon_{\mathrm{p}}}}=\left(\begin{array}{ccc}
-2 \bar{v} \frac{\Delta \sigma}{\bar{E}_{\mathrm{s}}} & 0 & 0 \\
0 & \frac{(1-\bar{v}) \Delta \sigma}{E_{\mathrm{s}}} & 0 \\
0 & 0 & \frac{(1-\bar{v}) \Delta \sigma}{E_{\mathrm{s}}}
\end{array}\right) \\
& =\left(\begin{array}{ccc}
-2 v \frac{\Delta \sigma}{E} & 0 & 0 \\
0 & \frac{(1-v) \Delta \sigma}{E} & 0 \\
0 & 0 & \frac{(1-v) \Delta \sigma}{E}
\end{array}\right)+\left(\begin{array}{lll}
-2 \Delta \varepsilon_{\mathrm{p}} & 0 & 0 \\
0 & \Delta \varepsilon_{\mathrm{p}} & 0 \\
0 & 0 & \Delta \varepsilon_{\mathrm{p}}
\end{array}\right)
\end{aligned}
$$

A coefficient $K_{v}$ and a fictitious elastic equivalent strain $\Delta \varepsilon_{\mathrm{eq}_{\mathrm{e}}}$, calculated considering an elastic behaviour, are now introduced as:

$\Delta \varepsilon_{\mathrm{eq}}=K_{v} \Delta \varepsilon_{\mathrm{eq}}$

From that, we obtain:

$$
\begin{aligned}
\Delta \varepsilon_{\mathrm{eq}} & =\sqrt{\frac{2}{3}\left(\left(\Delta \varepsilon_{1}-\Delta \varepsilon_{2}\right)^{2}+\left(\Delta \varepsilon_{1}-\Delta \varepsilon_{3}\right)^{2}+\left(\Delta \varepsilon_{2}-\Delta \varepsilon_{3}\right)^{2}\right)} \\
& =\frac{2(1+\bar{v})}{3} \frac{\Delta \sigma}{E_{\mathrm{s}}}=K_{v} \frac{2(1+v)}{3} \frac{\Delta \sigma_{\mathrm{el}}}{E}
\end{aligned}
$$




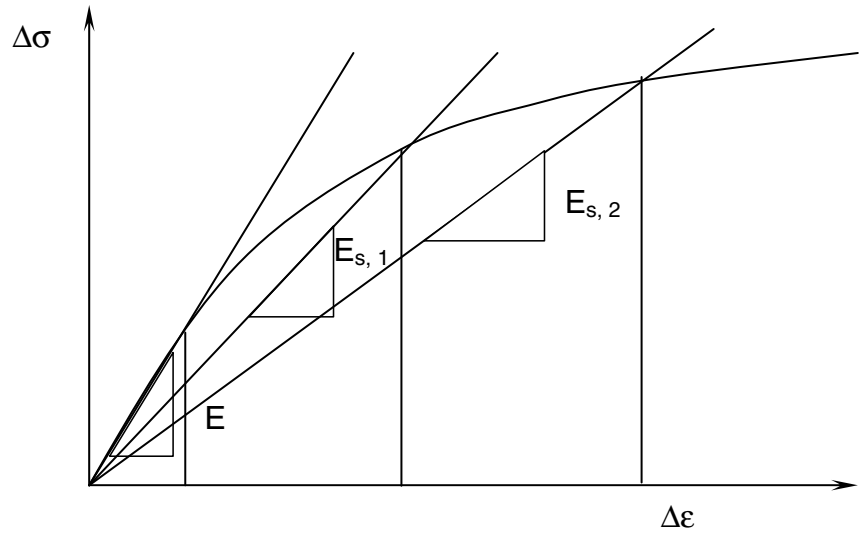

Fig. A1. Definition of a secant modulus $E_{\mathrm{s}}$ on an uniaxial curve.

$\Delta \sigma_{\mathrm{el}}$ is the fictitious stress calculated considering an elastic behaviour for the same temperature range on surface $\Delta T$.

In the case of thermal shock on a free wall: $\Delta \sigma=\frac{E_{s} \alpha \Delta T}{(1-\bar{v})}$ and: $\Delta \sigma_{\mathrm{el}}=\frac{E \alpha \Delta T}{(1-v)}$

Finally : $K_{v}=\frac{1+\bar{v}}{1-\bar{v}} \frac{1-v}{1+v}$

In conclusion, when the stress state is perfectly biaxial, the main steps of the RCC-MR method are:

(1) Estimation from the cyclic stabilized curve $\Delta \sigma-\Delta \varepsilon$ of a secant modulus $E_{\mathrm{s}}$ to take a non-pure elastic behaviour into account.

(2) Estimation of a modified Poisson's value $\bar{v}$ which ranges between 0.3 for elasticity and 0.5 for full plasticity.

(3) Deduction of stress-strain relations deduced from applying the Hooke's elasticity equations.

\section{A.2. Case where the stress state is not quite perfectly biaxial}

Hooke's relations between strains and stresses give:

$$
\begin{aligned}
\Delta \varepsilon_{\mathrm{eq}} & =\frac{\sqrt{2}}{3}\left(\left(\Delta \varepsilon_{x x}-\Delta \varepsilon_{y y}\right)^{2}+\left(\Delta \varepsilon_{x x}-\Delta \varepsilon_{z z}\right)^{2}+\left(\Delta \varepsilon_{y y}-\Delta \varepsilon_{z z}\right)^{2}\right)^{1 / 2} \\
& =\frac{2}{3}\left(\frac{1+\bar{v}}{1-\bar{v}}\right) e\left(1+3\left(\frac{1-\bar{v}}{1+\bar{v}}\right)^{2} \delta^{2}\right)^{1 / 2}
\end{aligned}
$$

with: $e=\frac{\Delta \varepsilon_{y y}+\Delta \bar{z}_{z z}}{2}$ and: $\delta=\frac{\Delta_{i z z}-\Delta \varepsilon_{y y}}{\Delta \dot{z}_{z z}+\Delta \varepsilon_{y y}}$

The same relationship would have been found for an elastic computation, but with the Poisson ratio $v$. Coefficient $K_{v}$ is:

$$
\begin{aligned}
K_{v} & \left.=\frac{\Delta \varepsilon_{\mathrm{eq}}}{\Delta \varepsilon_{e q_{\mathrm{e}}}}=\frac{1+\bar{v}}{1-\bar{v}} \frac{1-v}{1+v} \frac{1+3 \delta^{2} \bar{\mu}^{2}}{1+3 \delta^{2} \mu^{2}}\right)=K_{v \mathrm{~b}}\left(\frac{1+3 \delta^{2} \bar{\mu}^{2}}{1+3 \delta^{2} \mu^{2}}\right) \\
& =K_{v \mathrm{~b}}\left(\frac{1+\frac{3 \delta^{2} \mu^{2}}{K_{v \mathrm{~b}}^{2}}}{1+3 \delta^{2} \mu^{2}}\right)=K_{v \mathrm{~b}}\left(\frac{1+3 \frac{\gamma^{2}}{K_{v \mathrm{~b}}^{2}}}{1+3 \gamma^{2}}\right)
\end{aligned}
$$

with: $\mu=\frac{1-v}{1+v} \bar{\mu}=\frac{1-\overline{\bar{v}}}{1+\bar{v}} \gamma=\mu \delta=\frac{\Delta \sigma_{z z}-\Delta \sigma_{y y}}{\Delta \sigma_{z z}+\Delta \sigma_{y y}}$ and $K_{v \mathrm{~b}}$ representing a perfect biaxial state $(\delta=0)$.

\section{Appendix B. Viscous effects are negligible in the temperature range used for presented fatigue tests $(0.033 \leqslant f \leqslant 1 \mathrm{~Hz})$ [36]}

Figs. B1 and B2 show that frequency effect is negligible on fatigue behaviour of $304 \mathrm{~L}$ steel at $165^{\circ} \mathrm{C}$. However, when a lower test temperature is used (as room temperature or $T=90^{\circ} \mathrm{C}$ ), a viscous deformation and an effect of strain rate may be observed.

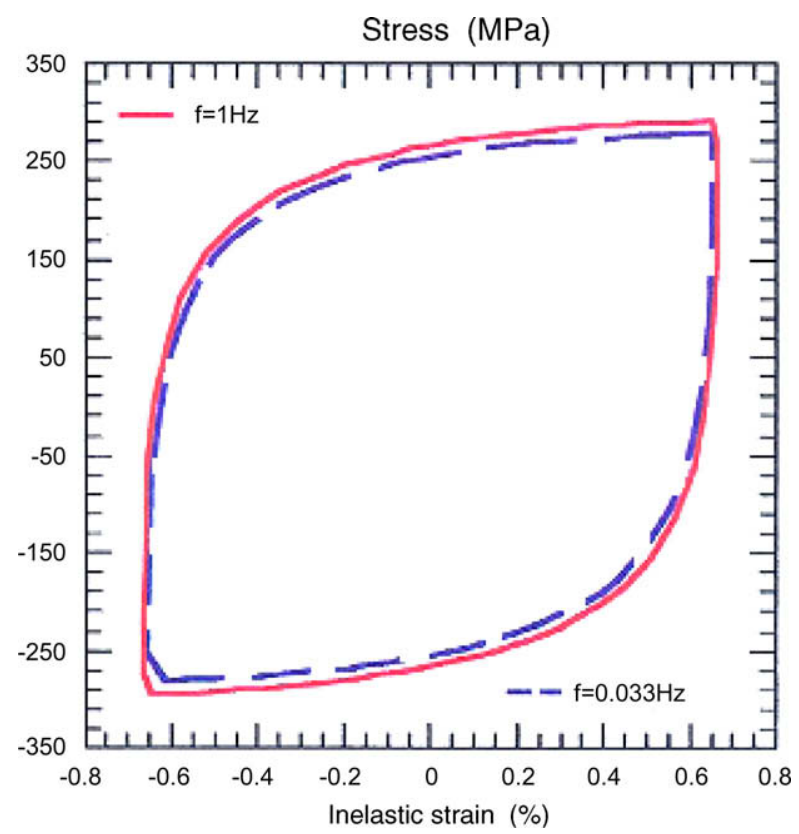

Fig. B1. Impact of loading frequency on fatigue loop stress as a function of inelastic strain when $\varepsilon_{\mathrm{t}}= \pm 0.8 \%$ and $T=165^{\circ} \mathrm{C}$.

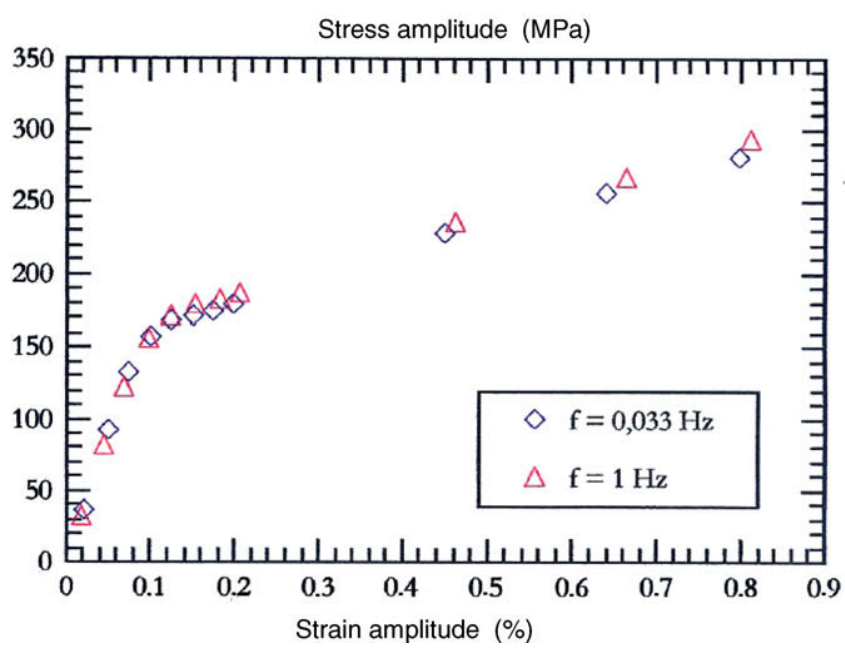

Fig. B2. Impact of loading frequency on stabilized stress-strain behaviour.

\section{References}

[1] Spera DA, Mowbray DF. What is thermal fatigue? Thermal fatigue of materials and components. ASTM STP 1976;612:3-9.

[2] Bressers J, Rémy L. Fatigue under thermal and mechanical loading. Kluwer Publishers; 1996.

[3] Burlet H, Vasseur S, Cailletaud G, Pineau A. fatigue crack growth under thermomechanical loading - application to life prediction of centrifugal casting equipment. High temperature fracture mechanisms and mechanics EGF 6. Mechanical Engineering Publishers; 1990. p. 379-95.

[4] De Keroulas F, Thomeret B. Fissuration par fatigue thermique de tuyauteries auxiliaires du circuit primaire principal: analyse des cas rencontrés Contribution des expertises sur matériaux à la résolution des problèmes rencontrés dans les réacteurs à eau pressurisée. SFEN, vol. 1; 1990. p. 107-17 [in French].

[5] Crutzen S, Birac C, Champigny F, Dugue C, Benoist P. Programme for inspection of steel components. Int Symp Fontevraud III 1994:404(1):66-73.

[6] Cipière MF, Le Duff JA. Thermal fatigue experience in French piping. International Institute of Welding, Lubjana, Slovenia; 2001 [Document no. XIII - 1891-01].

[7] Stephan JM, Curtit F, Vinndeirinho C, Taheri S, Akamatsu M, Peniguel C. Evaluation of the risk of damages in mixing zones. In: Blom AF, editor, Fatigue 2002, EMAS 3; 2002. p. 1707-14. 
[8] Fissolo A, Forestier A, Chapuliot S, Gourdin C, Magnaud JP, Ducros F, et al. Advances in thermal fatigue investigations performed in CEA for French PWR piping. In: Proceedings of third international conference on fatigue of reactor compounds. EPRI, US NRC, OECD NEA; 2004.

[9] Fissolo A, Marini B, Nais G, Wident P. Thermal fatigue behaviour for a $316 \mathrm{~L}$ type steel. J Nucl Mater (Netherlands) 1996;233-237(1-3):156-61.

[10] Maillot V. Amorçage et propagation de réseaux de fissures de fatigue thermique dans un acier inoxydable austénitique de type X2 CrNi18-09 (AISI 304L). CEA report R-6041; 2003, PhD Thesis, Ecole Centrale de Lille.

[11] Maillot V, Degallaix G, Degallaix S, Fissolo A. Biaxial thermomechanical fatigue on 304L-type austenitic stainless steel. MP Materialprüfung 2006;48(12):43-9.

[12] Fissolo A. Fissuration en fatigue thermique des aciers inoxydables austénitiques, CEA Report R-5982, Mémoire d'Habilitation à Diriger les Recherches; 2001. Université des Sciences et Technologie de Lille [in French].

[13] Chapuliot S, Ancelet O, Payen T, Mathet E. OCDE benchmark on thermal fatigue problem. In: Proceedings of the third conference on fatigue of reactor components. EPRI, US NRC, OECD NEA; 2004.

[14] Ancelet O. Etude de l'amorçage et de la propagation des fissures sous chargement cyclique. CEA Report R-6109, PhD thesis; 2006, University of Poitiers, France [in French]

[15] Ancelet O, Chapuliot S, Hennaf G, Marie S. Development of a test for the analysis of the harmfulness of a 3D thermal fatigue loadings in tubes. Int J Fatigue 2007;29:549-64.

[16] Suresh S. Fatigue of materials. Cambridge solid state science series, First paperback edition. Cambridge University Press; 1991.

[17] Miller KJ. Materials science perspective of fatigue resistance. Mater Sci Technol 1993;9(6):453-62.

[18] Marsh DJ. A thermal-shock fatigue study of type-304 and type-316 stainless steels. Fatigue Eng Mater Struct 1981;4(2):179-95.

[19] Faidy C, Le Courtois T, de Fraguier E, Le Duff JA, Le François A, Dechelotte J. Thermal fatigue in French RHR system. In: International conference on fatigue of reactor components.

[20] Vincent L, Malésys N, Chaise S, Perez G. Fatigue à grand nombre de cycles d'un acier inoxydable austénitique, Colloque National MECAMAT; 2007, Aussois, France.

[21] Maillot V, Degallaix G, Degallaix S, Fissolo A. Thermal fatigue crack networks parameters and stability: an experimental study. Int J Solids Struct 2004;42(2):759-69.

[22] Petrequin P, Mottot M, Rabbe P, Amzallag C, Vallibus L, Grattier G. Allowing for low cycle fatigue in the construction of fast sodium cooled reactors. Mécanique Matériaux, Eléctricité;323/324:34-41.

[23] RCC-MR French code. Association Française pour les Règles de conception et de construction des Chaudières Electro-Nucléaires [Edition 2002].

[24] Cast3M documentation. http://www.cast3m.cea.fr; 2007.

[25] Constantinescu A, Charkaluk E, Lederer G, Verger L. A computational approach to thermomechanical fatigue. Int J Fatigue 2004;26:805-18.

[26] Thomas JJ, Verger L, Bignonnet A, Charkaluk E. Thermomechanical design in the automotive industry. Fatigue Fract Eng Mater Struct 2004;27(10):887-95.

[27] Gerland M, Alain R, Ait Saadi B, Mendez J. Low cycle fatigue behaviour in vacuum of a 316L-type austenitic stainless steel between 20 and $600{ }^{\circ} \mathrm{C}$. II. Dislocation structure evolution and correlation with cyclic behavior. Mater Sci Eng A 1997;A229(1-2):68-86.

[28] Lemaitre J, Chaboche JL. Mécanique des matériaux solides. Dunod; 1998.

[29] Roche RL. Correction for Poisson's effect in the elastic analysis of low cycle fatigue; 1984 [Note CEA-N 2389].
[30] Moulin D, Roche RL. Int J Press Vess Piping 1985;19:213-33.

[31] Amiable S, Chapuliot S, Constantinescu A, Fissolo A. A computational of lifetime prediction methods for a thermal fatigue experiment. Fatigue Fract Eng Mater Struct 2004;28(7):692-706.

[32] Amiable S. Prédiction de durée de vie des structures sous chargement de fatigue thermique, PhD Thesis; 2006, University of Versailles.

[33] Levaillant C. Approche métallographique de l'endommagement d'aciers inoxydables austénitiques sollicités en fatigue plastique ou en fluage, $\mathrm{PhD}$ Thesis 1984, University of Technology of Compiègne [in French].

[34] Fissolo A, Amiable S, Vincent L, Constantinescu A, Chapuliot S, Stelmaszyk JM Thermal fatigue appears to be more damaging than uniaxial isothermal fatigue: a complete analysis of the results obtained on the CEA thermal fatigue device SPLASH. Pressure vessel and piping; 2006 [Paper No. PVP2006ICPVT11-93658].

[35] Robertson C, Fivel MC, Fissolo A. Dislocation substructure in 316L stainless steel under thermal fatigue up to $650 \mathrm{~K}$. Mater Sci Eng A 2001;315(12):47-57.

[36] Kaleta J, Zietek G. Representation of cyclic properties of austenitic steels with plasticity induced martensitic transformation. Fatigue Fract Eng Mater Struct 1998:955-64.

[37] Remy L. Recent development in thermal fatigue. Mechanical Engineering Publications; 1990. pp. 353-77.

[38] Haddar N. Fatigue thermique d'un acier inoxydable austénitique $304 \mathrm{~L}$ simulation de l'amorçage et de la croissance des fissures courtes en fatigue isotherme et anisotherme, PhD Thesis; 2003. Ecole Supérieure des Mines de Paris [in French].

[39] Keisler J, Chopra OK, Shack WJ. Statistical models for estimating fatigue strainlife behavior of pressure boundary materials in light reactor environments. Nucl Eng Des (Switzerland) 1996;167(2):129-54.

[40] Chopra OK, Chung HM, Kassner TF, Park JH, Schack WJ, Zhang J, et al. Current research on environmentally assisted cracking in light water reactor environments. Nucl Eng Des (Switzerland) 1999;194(2-3):205-23.

[41] Chopra OK, Shack WJ. Effect of LWR coolant environments on fatigue crack initiation in carbon and low alloy steels and austenitic stainless steels. In: Proceedings of third international conference on fatigue of reactor components. EPRI, US NRC, OECD NEA; 2004.

[42] Braillard O, Jamy Y, Balmigere G. Thermal load determination in the mixing Tee impacted by a turbulent flow generated by two fluids at large gap of temperature, Icone 13-50361. In: 13th international conference on nuclear energy; 2005.

[43] Sines G. Behaviour of metals under complex stresses. In: Sines G, Weisman JL, editors. Metal fatigue. New York: McGraw-Hill; 1959. p. 145-69.

[44] Crossland B. Torsion testing machines (Tension and torsion tests obtaining stress-strain data and torsion testing machine requirements). Developments in Materials testing machine design symposium. Institute of Mechanical Engineering, Manchester, England; 1965. p. 85-96.

[45] Dang Van K. On the resistance of metals to fatigue. Sci Tech l'Armement (Mémorial de l'Artillerie Française) 1973;47(3):647-722.

[46] Papadopoulos IV, Davoli P, Gorla C, Filippini M, Bernasconi A. A comparative study of multiaxial high-cycle fatigue criteria for metals. Int J Fatigue 1997;19(3):219-35.

[47] Socie D. Critical plane approaches for multiaxial fatigue damage assessment. Advances in multiaxial fatigue. ASTM STP 1191. McDowell/Ellis Editors; 1993 p. 7-36. 